\title{
Climate and the Emergence of Global Income Differences*
}

\author{
Thomas Barnebeck Andersen $^{\dagger}$, Carl-Johan Dalgaard ${ }^{\dagger \dagger}$ and Pablo Selaya ${ }^{\ddagger}$
}

First draft: April 18, 2010.

This version: March 28, 2015

\begin{abstract}
The latitude gradient in comparative development is a striking fact: as one moves away from the equator, economic activity rises. While this regularity is well known, it is not well understood. In the present paper we take a step towards unpacking this gradient. Perhaps the strongest correlate with (absolute) latitude is the intensity of ultraviolet radiation (UV-R), which epidemiological research has shown to be a cause of a wide range of diseases. We establish that UV-R is strongly and negatively correlated with economic activity, both across and within countries. We propose, and test, a mechanism that links UV-R to current income differences via the impact of disease ecology on the timing of the take-off to sustained growth.
\end{abstract}

Keywords: Comparative development, climate, UV radiation, disease ecology, fertility transition, take-off to modern economic growth

JEL Codes: O11; I00; Q54

\footnotetext{
* We would like to thank Daron Acemoglu, Philippe Aghion, Roland Benabou, Raquel Fernandez, Oded Galor, Moshe Hazan, Peter Sandholt Jensen, Chad Jones, Nicolai Kaarsen, David Mayer, Stelios Michalopoulos, Fidel Perez-Sebastian, James Robinson, Uwe Sunde, Jon Temple, David Weil, Fabrizio Zilibotti, and seminar participants at a number of conferences and workshops. Lise Hansen provided excellent research assistance. This research was supported by the European Commission within the project "Long-Run Economic Perspectives of an Aging Society" (LEPAS) in the Seventh Framework Program under the Socio-economic Sciences and Humanities theme (Grant Agreement: SSH7-CT-2009-217275). A previous version of the paper was circulated under the title "Eye Disease and Development."

† Department of Business and Economics, University of Southern Denmark. Email: barnebeck@sdu.sam.dk.

†'Department of Economics, University of Copenhagen, and CEPR. Email: Carl.Johan.Dalgaard@econ.ku.dk.

‡ Department of Economics, University of Copenhagen. Email: Pablo.Selaya@econ.ku.dk.
} 


\section{Introduction}

One of the sturdiest regularities in comparative economic development involves the location of a country vis-à-vis the equator and its level of prosperity. As one moves away from the equator in either direction, the level of income per capita goes up. While the link is well known, it is not well understood.

Perhaps the strongest among the correlates of absolute latitude is the intensity of UV radiation (UV$\mathrm{R})$; the cross-country correlation coefficient is -0.95 . Moreover, there are good reasons to believe that UV-R could exert an impact on development via morbidity. In a survey prepared for the World Health Organization, Lucas et al. (2008) identifies a range of afflictions for which convincing epidemiological evidence exist in favor of a causal impact from high UV exposure. The list includes a set of cancers as well as debilitating eye diseases. Consequently, the present study investigates whether differences in UV-R have left an imprint on comparative economic development, and in so doing we hope to learn more about the underlying causes of the striking latitude gradient in economic development.

In the first part of the paper we examine the reduced-form link between UV-R and economic activity at different levels of aggregation. We first explore cross-country variation. Even when we account for a very demanding set of geographic and climate-related characteristics-latitude included among them-UV-R emerges as a strong correlate of economic activity. This remains the case when we condition on aspects of institutional infrastructure and the cultural fabric of individuals societies; and when we control for diseases that are epidemiologically independent of UV-R, but happens to be more pervasive in regions closer to the equator, where UV-R is greatest. We next examine the UVR/economic-activity nexus at the sub-national level, where the unit of analysis is pixels of size 1degree latitude by 1-degree longitude (we also explore other pixel size configurations for robustness reasons). In the pixel setting we can prune the data quite decisively for countrywide political institutions and cultural values through country fixed effects while also controlling for relevant (local) geographic and climatic correlates of UV-R and economic activity. Moreover, by including languagegroup fixed effects we aim to shut down potential channels operating through unobserved withincountry variation in cultural characteristics. In spite of this extensive set of covariates, UV-R remains a significant determinant of economic activity, whether measured by (PPP) GDP per capita orfollowing Henderson et al. (2012)—by the intensity of nightlights.

In the second part of the paper we propose a mechanism behind the reduced-form link between UV-R and economic development, which we subsequently submit to a series of tests. In this endeavor we draw on a recent strand of growth research, which attempts to elucidate the mechanics of development over the very long run; i.e., from Malthusian stagnation to sustained economic growth (e.g., Galor and 
Weil, 2000; Galor and Moav, 2002; Lucas, 2002; Hansen and Prescott, 2002; for a survey, see Galor, 2011). The main proposition of this literature, in terms of comparative economic development, is that the differential timing of the fertility transition shaped the global distribution of income. Theoretically, the fertility transition is vital in that it both reduces capital dilution, thus enabling per capita growth to take hold, and unleashes a reinforcing virtuous circle involving rising human capital levels and technological innovation. Accordingly, if diseases related to UV-R have influenced the timing of the fertility transition, and thereby the emergence of sustained economic growth, this could be an important explanation for our reduced-form results.

A potential channel through which disease ecology may have influenced the timing of the fertility transition is by affecting work-life expectancy as a skilled worker; i.e., through a lower inherent return to skill investments in places with a greater disease burden (e.g., Cervelatti and Sunde, 2013; Galor, 2010; Hazan and Zoabi, 2006). Guided by the epidemiological literature, we argue that cancers related to UV-R are unlikely to be the cause of cross-country differences in work-life expectancy as a skilled worker. However, debilitating eye diseases could have this effect, for two reasons. First, loss of visual acuity is likely to be particularly problematic in skill-intensive occupations, where the ability to read and write is of utmost importance. Second, the incidence of UV-R related eye disease is unevenly distributed around the world. When we invoke existing ophthalmological surveys of cataract prevalence-the most important UV-R related eye disease-and calculate work-life expectancy in different geographic regions, we find that observed prevalence rates can create a gap in expected work life of as much as 14 years when comparing high and low UV-R regions. ${ }^{1}$ While cataract only appears as an old-age condition in Western Europe, it emerges considerably earlier in life, and proceeds to increase at greater speed with age, in regions closer to the equator. It is therefore plausible that differences in (historical) eye disease incidence have led to variation in the perceived return to skill accumulation around the world. Consequently, the main reason why UV-R is a strong correlate of economic activity may be that it picks up the influence from the differential timing of the fertility transition and thus the take-off to sustained growth.

In order to examine whether this mechanism can account for the UV-R/income gradient, we perform a number of consistency checks. We first document that the cross-country gradient emerges during the $20^{\text {th }}$ century; it did not exist in previous centuries. UV only appears to become a relevant determinant of prosperity after the first emergence of the fertility transition, which is consistent with the hypothesis that UV-R becomes a growth determinant via its influence on the timing of the transition

\footnotetext{
${ }^{1}$ Cataract is a clouding of the lens, which leads to blurred vision and ultimately blindness. It remains the single biggest cause of preventable blindness worldwide, for which reason the UN's "vision 2020" campaign-a program that was part of the Millennium Development Goals and aims to reduce preventable blindness by half before 2020—specifically targets cataract.
} 
and the ensuing human capital investments. Second, we document that UV-R is in fact a strong determinant of the onset of the fertility transition. Moreover, we find that the fertility transition is itself a strong determinant of current cross-country income differences, consistent with the predictions of the above-mentioned theoretical literature. According to our estimates, the link between UV-R and the timing of the fertility transition is quantitatively large enough to account for the bulk of the reduced-form estimate of the impact of UV-R on present-day prosperity. Third, consistent with a pivotal role of the fertility transition in unleashing a process of human capital accumulation, we find that UV-R is a significant determinant of human capital investments since 1870. Fourth, UV-R loses significance once we control for its more proximate causes: eye disease and the timing of the fertility transition. Finally, to gauge the relevance of the hypothesized causal mechanism at the sub-regional level, we examine the link between UV-R and income per capita within two countries: the US and China. As demonstrated in Bleakley and Lange (2009) and Hansen et al. (2014), fertility patterns within the US were strongly influenced by schooling. In theory, the mechanism under scrutiny should therefore be operative, for which reason we expect UV-R to be negatively correlated with economic activity within the US. In contrast, the fertility transition in China was highly influenced by government policy: in particular the "later, longer, fewer" policy of the early 1970s and the one-child policy that was enacted in the late 1970s (Bongaarts and Greenhalgh, 1985). Hence climate-related determinants of the return to human capital should be of less consequence to comparative development within China. Consistent with these priors, our analysis demonstrates an impact from UV-R within the US, but not within China.

Our paper is related to several strands of literature. First, it is related to the literature on growth in the very long run, as discussed above. A few papers have empirically examined (aspects of) the links between return to education, the fertility transition, and contemporary development (e.g., Bleakley and Lange 2009; Bleakley 2007; Becker et al. 2010; Becker and Woessman 2009). The key difference between the present study and existing research on the topic revolves around the nature of the diseases under study as well as in the global outlook of the present study. ${ }^{2}$ Second, our paper contributes to the macro literature, which examines the impact of mortality and morbidity on development (e.g., Gallup and Sachs, 2001; Young, 2005; Acemoglu and Johnson, 2007; Weil, 2007; Ashraf, Lester and Weil, 2008; Lorentzen, McMillan and Wacziarg, 2008; Aghion, Howitt and Murtin, 2010; Cervellati and Sunde, 2011). Overall, our work suggests that morbidity holds strong explanatory power vis-à-vis contemporary income differences. ${ }^{3}$ Finally, the present paper is related to a recent empirical literature,

\footnotetext{
${ }^{2}$ To be sure, there are global (cross-country) studies of the individual links. Murtin (2013), Herzer et al. (2012), and Angeles (2010), for instance, investigate the link between education and fertility in a cross-country context, whereas Glaeser et al. (2004) do so for the link between schooling and growth. For some interesting regional evidence on the latter link, see Gennaioli et al. (2013).

${ }^{3}$ Our results also imply that contemporaneous improvements in morbidity (eye disease, in particular) may not have large effects on growth going forward, since the impact we observe today is likely the accumulated
} 
which argues that climate and deep historical factors have helped shape the contemporary income distribution (e.g., Olsson and Hibbs, 2005; Nunn, 2008; Feyrer and Sacerdote, 2009; Ashraf and Galor, 2013; Michalopoulos and Papaioannou, 2013; for a survey, see Nunn, 2014).

We proceed as follows. In the next section we provide evidence of a reduced-form link between UV$\mathrm{R}$ and economic activity, both at the country and the sub-national level. Subsequently, Section 3 explores the hypothesized mechanism, which links UV-R to global income disparities. Section 4 concludes.

\section{UV-R and Development: The Reduced Form}

\subsection{Cross-Country Analysis: Specification}

The specification we use to analyze the cross-country data is the following:

$$
\log \left(y_{i}\right)=\beta_{0}+\beta_{1} \log \left(u v_{i}\right)+Z_{i}^{\prime} \gamma+u_{i}
$$

where $\log \left(y_{i}\right)$ is either GDP per worker or GDP per capita in country $i$; $\log \left(u v_{i}\right)$ measures the intensity of UV-R in country $i$; and $Z_{i}$ is a vector of auxiliary controls. The parameter of interest is $\beta_{1}$.

When estimating equation (1) by OLS, our main concern is omitted variable bias. Inspired by the literature on the fundamental determinants of productivity (see Acemoglu, 2009, Ch. 4), we attempt to minimize the risk that our estimates of $\beta_{1}$ are convoluting the influence from known productivity determinants by controlling for an extensive set of potential confounders.

UV-R features a very strong latitude gradient. Since latitude may capture a host of income determinants, we include it in $Z$. In our regressions, we allow absolute latitude to enter in two ways: linearly and as latitude fixed effects. The latitude fixed effects are constructed such that each 10degree latitude bin is allowed to hold a separate impact on our income measures. In our full specification, identification is therefore obtained from the residual variation in UV-R that is orthogonal to absolute latitude. ${ }^{4}$

Two other climate/geography traits cause variation in UV-R beyond absolute latitude, namely cloud cover and elevation. In places with more cloud cover, UV-R is (usually) lower; and at higher altitudes,

outcome of past events. In this sense our results strikes something of a middle ground between previous contributions that suggest the impact from health on productivity is modest or negative, at least in the short to medium run (see Young, 2005; Acemoglu and Johnson, 2007; Ashraf, Lester and Weil, 2008), and contributions that uncover a strong positive impact on growth (e.g., Gallup and Sachs, 2001; Lorentzen, McMillan and Wacziarg, 2008).

${ }^{4}$ Since UV-R is not decreasing linearly in latitude, latitude fixed effects serves to prune UV-R in a demanding way from its correlation with latitude. 
UV-R is higher. Since cloud cover and nation-specific topography do not track latitude fully, these features provide variation in UV-R that is orthogonal to latitude. ${ }^{5}$

Are these residual sources of variation problematic from the point of view of isolating an impact from UV-R on prosperity? Clearly, the elevation of a country above sea level may have independent effects on long-run productivity. For instance, Diamond (1997) discusses the challenges involved in developing complex societies in mountainous regions. If high-altitude regions had a historical growth disadvantage, the ramifications may be felt to this day. This would naturally complicate the interpretation of a correlation between (residual) UV-R and current economic development.

We confront this issue in several ways. First, we control for elevation directly. Much like latitude, elevation is measured in two ways: linearly and as elevation fixed effects. Specifically, every 500 meters of additional altitude is allowed an individual effect. Second, we control for the likely implications of topographical differences for long-run development. This entails controlling for the timing of the Neolithic Revolution; if Diamond (1997) is correct, this should capture the indirect impact of elevation. Moving beyond the Diamond thesis, elevation may have a contemporary direct effect on productivity via trade costs; we try to capture trade costs by including distance to coast and navigable river in the control set. Naturally, climatic conditions change with altitude, which we capture by controlling for both average temperature and precipitation. More generally, in an effort to ensure that our estimates are not confounding a spurious link between UV-R and climatic conditions of particular relevance to agriculture, we also control for soil quality, the share of the country situated in the tropical climate zone, and the average number of frost days per year. ${ }^{6}$ In the baseline control set we also include the size of the country, and we add continental fixed effects to capture unobserved heterogeneity. ${ }^{7}$

When we control for this extensive set of variables, the variation in UV-R that we exploit should essentially be due to variation in cloud cover, as the auxiliary determinants of UV-R are controlled for

\footnotetext{
${ }^{5} \mathrm{~A}$ third factor that in principle affects UV-R is the thickness of the ozone layer, which may raise the concern that reverse causality cannot be ruled out $a$ priori. But there is clearly no simple link between human activity at a particular location and the ozone layer at the selfsame location. A good illustration of this are the ozone holes over the North Pole and the Antarctica, which surely are not the result of local human activity. Accordingly, while UV-R may be endogenous at the global level, local UV-R is not endogenous to local economic activity. In Section 1 of the Supplementary Appendix we provide an extensive discussion of the causes of variation in UV-R. Moreover, we provide a direct test of the claim that (local) economic activity does not influence (local) UV-R; see Table A1. Consequently, we trust that reverse causality is not a concern in the present analysis.

${ }^{6}$ Ashraf and Galor (2011) use the same soil quality variable to control for agricultural productivity; Gallup and Sachs (2000) demonstrate a detrimental impact from tropical climate on agricultural yields; whereas Masters and McMillan (2001) employ 'frost' in a similar vein.

${ }^{7}$ There are many reasons why scale could matter to economic development, motivating the inclusion of country area in the set of geographic controls. Olsson and Hansson (2011), for instance, develop a theory linking institutional development to country size. Country area is also known to influence the intensity of trade and travel (e.g., Frankel and Romer, 1999; Andersen and Dalgaard, 2011).
} 
in the regression. It is worth observing that the link between cloud cover and UV-R in practice is a complex one. Climatic research has demonstrated that the extent of cloud attenuation of UV-R depends on many different properties of the cloud cover, including cloud amount, cloud thickness, cloud type, relative position of the sun and the clouds, and the number of cloud layers (see Calbó et al., 2005). Surface UV-R is sometimes affected by clouds in such a manner that it is higher under partially cloudy than under cloudless conditions, an effect known as cloud enhancement. In general, clouds are one of the major uncertainties in the estimation and forecasting of UV-R trends (Calbó et al., 2005). Overall, we therefore believe that the variation we exploit is external, in the sense of Deaton (2012).

Nevertheless, there are at two lingering concerns. First, the UV-R variable may be spuriously correlated with (non UV-R related) diseases that just happen to be more pervasive in high UV-R areas. Second, UV-R may be correlated with institutions or cultural values, which in complex ways were influenced by climatic conditions.

In order to deal with the first concern we examine the robustness of our results to the inclusion of a range of tropically clustered diseases that are epidemiologically independent of UV-R. We also examine an affliction, which is epidemiologically related to UV radiation: skin cancer. These robustness checks leave the link between UV-R and prosperity largely unaffected, as shown in the Supplementary Appendix. ${ }^{8}$

In order to gauge the relevance of the second concern in a cross-country setting, we check the resilience of the UV/income gradient to additional indirect and direct controls for culture and institutions. Again, we find no indication that UV-R is simply picking up variation attributable to culture or institutions; these results are also found in the Supplementary Appendix. ${ }^{9}$ Moreover, we explore the hypothesis using within-country variation, as discussed below. In this setting we are able to control more decisively for institutions and/or cultural determinants of productivity.

\subsection{Cross-Country Analysis: Data}

Our dependent variables in this section are (PPP) GDP per worker and per capita in 2004, taken from Penn World Tables.

\footnotetext{
${ }^{8}$ These results are found in Tables A9 and A10 in the Supplementary Appendix.

${ }^{9}$ See the results reported in Tables A11 and A12 in the Supplementary Appendix.
} 


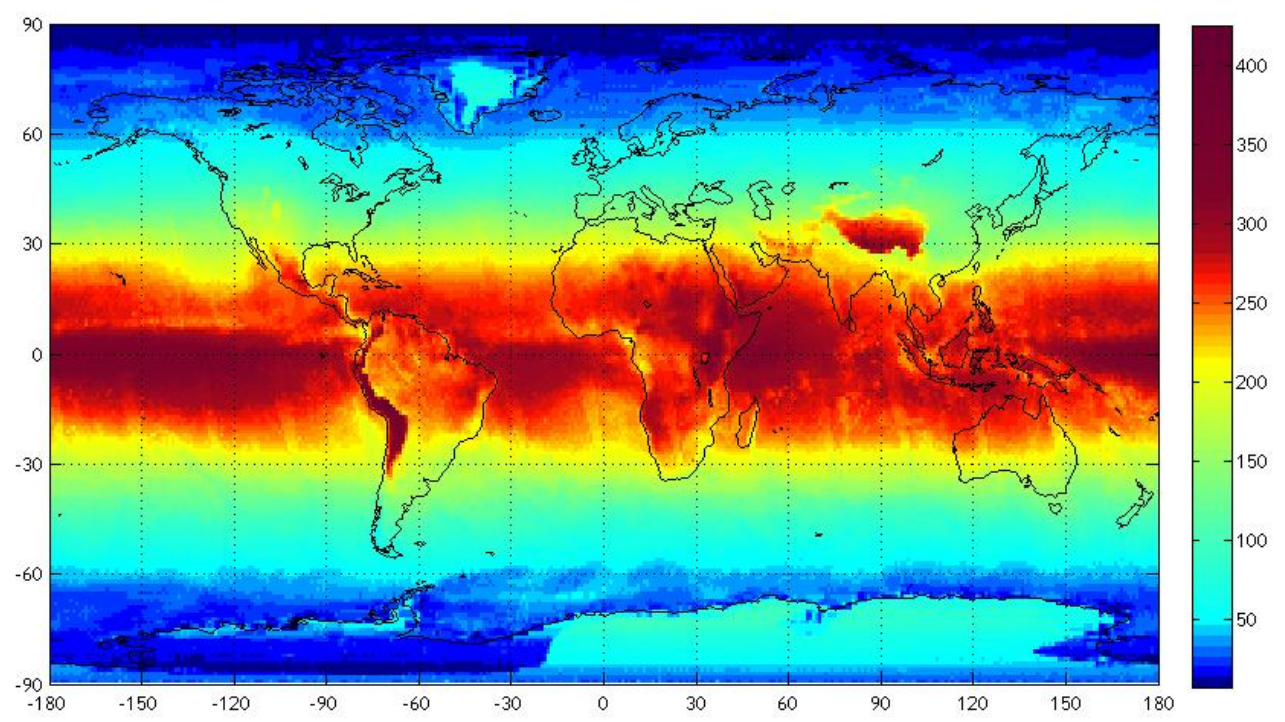

Figure 1: Global distribution of the UV-R variable. Notes: See Supplementary Appendix, Section 1, for details on the index.

Our principal independent variable is ultraviolet radiation (UV-R). UV-R is a form of electromagnetic radiation, which is found in sunlight. There are three types of UV-R: A, B, and C. These three varieties of UV-R are distinguishable by their wavelength: UVA radiation has the longest wavelength (yet shorter than visible light), UVC the shortest, with the UVB radiation wavelength being in between. Of the three forms of UV-R, UVC is considered the most harmful to humans. This form of electromagnetic radiation is fortunately filtered out by the earth's atmosphere, which leaves only UVA and UVB radiation with the potential to affect life forms on earth.

NASA produces daily satellite-based data for ambient UV-R. The UV index captures the strength of radiation at a particular location, and it is available in the form of geographic grids and daily rasters with pixel size of 1-degree latitude by 1-degree longitude. We rely on data for daily local-noon irradiances for 1990 and 2000 to produce average yearly UV-R levels for each country. That is, in our analysis below we employ an average of the 1990 and 2000 observations. ${ }^{10}$ Figure 1 provides a map depicting the global distribution of UV-R intensity; the correlation with latitude is visually obvious. Further details on the data, including the controls discussed in the previous section, summary statistics as well as correlations between the controls and UV-R are found in the Supplementary Appendix.

\subsection{Cross-Country Results}

\footnotetext{
${ }^{10}$ Though we invoke an average, the correlation between UV-R in 1990 and 2000 is above 0.99. In general, it seems that the intensity of surface UV-R has been relatively stable on earth during the last 2 billion years (Cockell and Horneck, 2001). Hence in a cross-section context current comparative UV-R levels are likely to by an excellent indicator of UV-R conditions a few centuries ago.
} 
The results from estimating equation (1) by OLS are reported in Tables 1 and 2, where the dependent variable is respectively GDP per worker and GDP per capita. The first column of Table 1 (Table 2) shows the bivariate association between (log) UV-R and (log) GDP per worker (GDP per capita). Inspection reveals that an increase in UV-R of one percent is associated with a reduction in labor productivity of approximately 1.3 percent (Table 1 ) and 1.5 percent in the context of GDP per capita (Table 2).

[Tables 1 and 2 about here]

In columns 2-7 of the two tables we add controls sequentially, and in columns 8-9 we include all controls simultaneously. Recall that we measure the influence from latitude and elevation in two different ways, which explains why we have two 'full specifications', cf. columns 8-9 of Tables 1-2. Regardless of which full specification we examine, however, we find that UV-R is significant at five percent or better in all columns. ${ }^{11}$

The controls have only a modest effect on the partial correlation between UV-R and living standards, despite the fact they themselves are relevant (see bottom of tables for F-tests), and despite the fact that the controls are strongly correlated with UV-R. For example, when all controls are added simultaneously in Table 1 , columns 8 and 9 , the UV-R elasticity is -1.50 and -1.46 , depending on how latitude and elevation are controlled for, which is close to the simple bivariate estimate of roughly $1.3 .^{12}$

Despite our best efforts to control for all relevant observable factors, we obviously cannot rule out that some omitted factor is correlated with both UV-R and income. To gauge just how concerned we should be about omitted variables, we invoke the insights of Altonji et al. (2005) that selection on observables can be used to assess the likely importance of bias arising from unobservable factors. Specifically, we calculate the bias-corrected estimate derived by Oster (2015), which generalizes the work of Altonji et al (2005). A robust result requires that the adjusted and the unadjusted estimate

\footnotetext{
${ }^{11}$ As a further robustness check we have examined whether any particular continent drives results. As shown in Tables A7 in the Supplementary Appendix, the results are qualitatively unaffected by dropping continents one at a time.

${ }^{12}$ As demonstrated in the Supplementary Appendix (Table A2), when all controls are included simultaneously they account for $94 \%$ (and 97\% with latitude and elevation fixed effects) of the variation in UV-R. Much of the reduction in the size of the UV-R estimate is thus plausibly attributable to the fact that UV-R is strongly correlated with e.g. latitude, which influences economic prosperity in various independent ways. On physical grounds, the remaining UV variation plausibly reflects variation in cloud cover, as discussed above.
} 
lead to similar conclusions. In the present case the bias-corrected estimate is -1.57 , which is quite close to the estimates found in Table 1 . We take this as a strong sign of robustness. ${ }^{13}$

In light of these considerations it is perhaps not surprising that additional controls - thought to capture institutional and/or cultural aspects of societies-appear to have little effect on the UV-R estimates reported above. This is demonstrated in the Supplementary Appendix (Tables A11-A14). Similarly, the point estimates reported above remain significant when we alternatively add controls for tropically clustered diseases. (Tables A9-A10).

Suppose then that the point estimate for UV-R is causal: Is the impact economically significant? Judging from column 9 of Table 2 we find an elasticity of UV-R with respect to GDP per capita of 1.7. To get a sense of economic significance, observe that one standard deviation reduction in (log) UV-R damage (about 0.5) implies about 0.85 log points increase in GDP per capita, which translates into an increase in the level of GDP per capita by roughly a factor of $2.3(=\exp (0.5 \times 1.7))$, or about 130 percent.

\subsection{Pixel Level Analysis: Specification}

We now move beyond the use of cross-country data in an effort to better control for variation in underlying institutions and cultural values. Accordingly, the unit of analysis is pixels at a 1-degree latitude by 1-degree longitude resolution (roughly $100 \mathrm{~km}$ by $100 \mathrm{~km}$ at the equator).

The regression specification is the following:

$$
\log \left(y_{i c}\right)=\beta_{1} \log \left(u v_{i c}\right)+Z_{i c}^{\prime} \gamma+\theta_{j c}+\varepsilon_{i c}
$$

where $\log \left(y_{i c}\right)$ is a measure of economic activity in pixel $i$ in country $c$. As in the cross-country setting we control for a host of confounders as represented by the vector, $Z_{i c}$, which also contains a constant term. $\theta_{j c}$ is either a language fixed effect (language groups are thus indexed by $j$ ) or a country fixed effect (in which case $\theta_{j c}=\theta_{c}$ ), and $\varepsilon_{i c}$ an error term.

\footnotetext{
${ }^{13}$ The formula for the bias corrected estimate that we employ is $\beta^{*}=\tilde{\beta}+(\stackrel{\circ}{\beta}-\tilde{\beta})\left[\left(R^{\max }-\tilde{R}\right) /(\tilde{R}-\stackrel{\circ}{R})\right]$ where $\tilde{\beta}$ is the point estimate when a full set of controls are admitted (here we use the result from Table 1, column 9), $\stackrel{\circ}{\beta}$ is the result when a minimal number of controls are included (we employ Table 1, column 1). $\tilde{R}, \stackrel{\circ}{R}$ are the associated $\mathrm{R}^{2}$ in the two specifications and $R^{\max }$ is the $\mathrm{R}^{2}$ in a hypothetical regression when all variables (observables and unobservables) are included; we let $R^{\max }=1$.
} 
In terms of the content of $Z_{i c}$, we follow the same strategy as invoked in the cross-country setting to the greatest extent possible. Hence we control for latitude, elevation, distance to coast or river, precipitation, temperature, and (pixel) area. ${ }^{14}$

Controlling for country-specific unobserved variation through country fixed effects amounts to controlling for country-specific institutions and cultural values. Most likely this should be enough to gauge whether the UV-R gradient is convoluting an influence from these fundamental determinants of productivity. Nevertheless, in light of recent research on the influence of culture on long-run prosperity (e.g., Tabellini, 2010; Michalopoulos and Papaioannou, 2013), one may legitimately worry that cultural values vary within countries. For this reason, we also include language fixed effects. The logic is that if the spoken language varies within a country then this likely signals cultural variation as well. This approach implies that when we examine economic activity at the $1 x 1$ resolution, we include in excess of 1000 (language) fixed effects in an effort to control for within country variation in cultural traits. The details on the construction of the language fixed effects are found in the Supplementary Appendix (Section 2).

The controls collectively capture most of the variation in UV-R. When we control for country fixed effects, in addition to the geographic controls, we span 95\% of the UV-R variation in the 1x1 setting; and slightly more than that when we instead include language fixed effects (see Table A4 in the Supplementary Appendix).

\subsection{Pixel-Level Analysis: Data}

Figure 2 depicts the geographic distribution of GDP per capita (2005 PPP-USD) at the 1x1 degree resolution. To check the robustness of the results we also estimate equation (2) in samples involving larger pixel sizes: 2x2 degrees latitude/longitude and 4x4 degrees latitude/longitude, respectively.

\footnotetext{
${ }^{14}$ Since the geographical size of a pixel varies across the globe (as one moves away from the equator), controlling for area is relevant in the present context as well.
} 


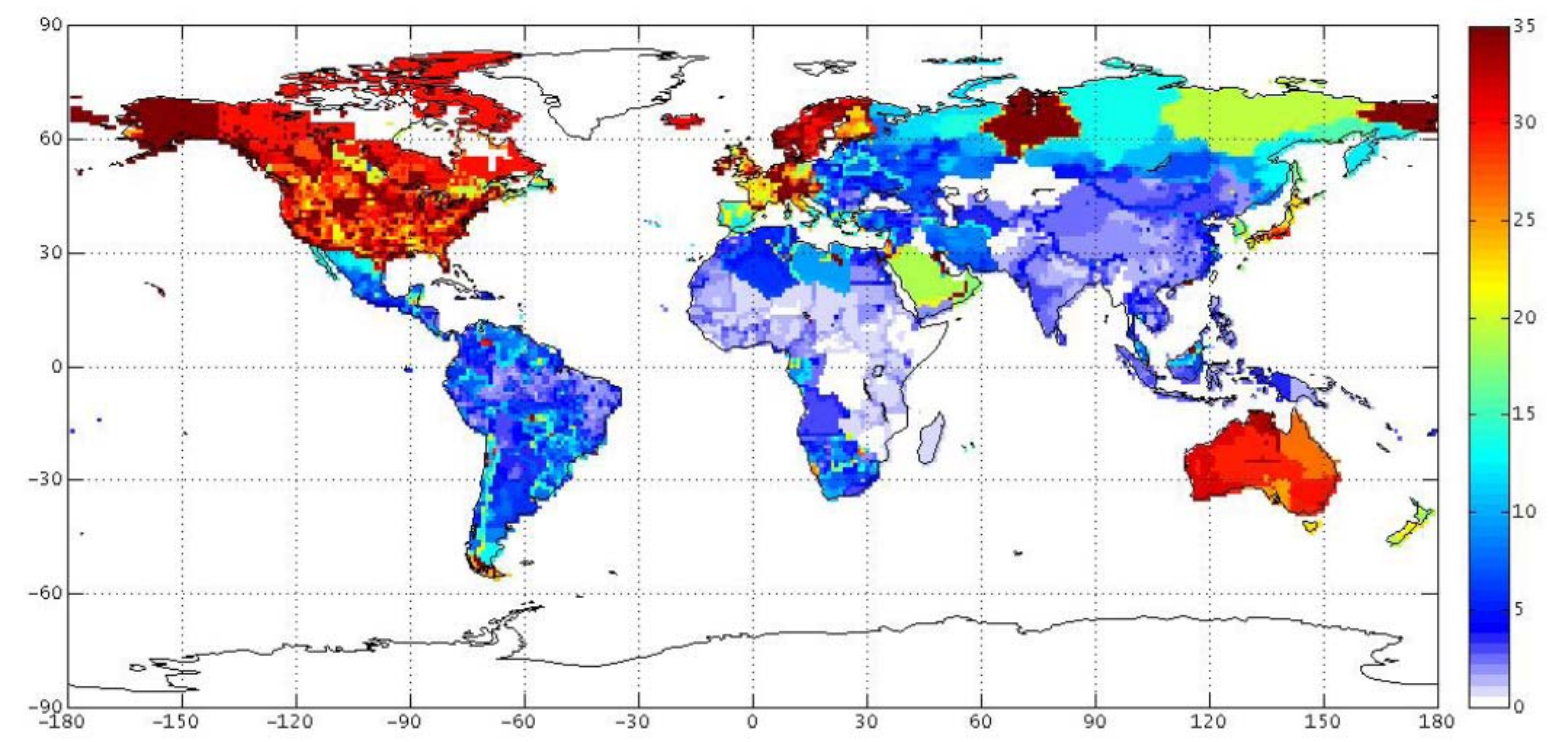

Figure 2: Real Gross Product Per Capita (2005 PPP-USD). Source: Yale G-ECON Project. Notes: See Supplementary Appendix for details.

Following Henderson et al. (2012) we also employ an alternative indicator of economic activity: satellite data on earthlights at night (or just nightlights). In sum, we measure economic activity in two different ways as well as at three different levels of aggregation.

The source of the UV-R data is the same as in the cross-country setting. As these data are available at the $1 \mathrm{x} 1$ degree latitude/longitude resolution, it is straightforward to employ them in the present setting. The sources of the controls included in $Z_{i}$ are described in the Supplementary Appendix.

\subsection{Pixel-Level Analysis: Results}

Table 3 reports the regression results when the dependent variable is (log) 2005 GDP per capita. The first three columns report results from the $1 \mathrm{x} 1$ resolution; the next three columns report results from the 2x2 resolution; and the final three columns report results from the $4 \times 4$ resolution. At each level of aggregation we first examine the partial correlation between UV-R and GDP per capita without any fixed effects; then with country fixed effects; and, finally, with a full set of language fixed effects. We report two sets of standard errors: standard errors that are clustered at the country level (in brackets) and Conley standard errors (in parenthesis).

[Table 3 about here]

As is evident upon inspection of Table 3, the auxiliary controls and UV-R together explain the bulk of the global variation in living standards. Reassuringly, UV-R is significant in all cases, i.e. both with and without country and language fixed effects, and at all levels of aggregation. 
Table 4 reports the results when we employ nightlights as a proxy for economic activity. As in the case of GDP per capita, the UV-R gradient is present at all three levels of aggregation, with or without the inclusion of country or language fixed effects. Moreover, the partial correlation is fairly stable. Overall, the regional analysis corroborates the results from the cross-country analysis: UV-R appears to exert a detrimental impact on prosperity.

[Table 4 about here]

The results from the cross-country and the pixel setting do however differ in one important respect, which is the economic size of the impact from UV-R on GDP per capita. As is apparent from columns 2 or 3 in Table 3, when UV-R is increased by one percent, GDP per capita drops by $0.18 \%$. This is a considerably smaller effect than the estimate of $1.6 \%$ obtained in the cross-country analysis (cf. Table 2, column 8). Another way to see the difference is by observing that one standard deviation reduction in UV-R (roughly 0.85 log points) implies an increase in GDP per capita of about $17 \%$ (= $\exp (0.85 \times 0.18)-1)$; down from $130 \%$ in the pure cross-country analysis.

What should we make of this change in economic significance? An obvious interpretation is that the cross-country analysis may be tainted by omitted variable bias, and apparently these omitted variables work to increase the economic significance of UV-R. If this interpretation is correct, the results from Tables 3 and 4 are more likely to convey accurate information about the causal influence from eye disease on long-term development than the results from Tables 1 and 2. Of course, the bias-corrected estimate calculated in Section 2.3 does not suggest omitted variables bias is a concern. Another interpretation is therefore that the results from Tables 3 and 4 are underestimating the impact from UV-R. Migration, in particular, is likely to be a much bigger issue in the context of the pixel analysis than in the cross-country setting; and if individuals tend to migrate to regions with higher productivity, which could be caused (in part) by less UV-R, this will reduce interregional income per capita variation and thus temper the impact from UV-R. The fact that the (absolute) size of the point estimate tends to increase as we move from $1 \times 1$ to $4 \times 4$ pixels is at least consistent with a migration account. Nevertheless, a conservative conclusion from the analysis would be to assume that an elasticity closer to 0.2 than 1.5 is the more plausible estimate for the impact of UV-R on long-run prosperity.

\section{UV-R and Development: A Mechanism}

\subsection{UV-R as a Measure of Disease Ecology}


The study by Lucas et al (2008) identifies two broad sets of health risks associated with excessive UV-R exposure. The first set of health risks is associated with a variety of skin cancers. ${ }^{15}$ Accordingly, UV-R could be detrimental to labor productivity through greater mortality. However, at closer inspection it seems unlikely that UV-R is a cross-country determinant of prosperity through a mortality mechanism. The reason is that natural selection likely has changed human skin pigmentation in the aftermath of the exodus from Africa, so as to strike a balance between harmful and beneficial consequences of UV-R. The principal benign role played by UV-R derives from it being a key source of vitamin D, which influences the immune system and thereby also longevity. Consequently, in highUV regions skin color turned darker, while in low-UV regions it became lighter. ${ }^{16}$ Obviously, this does not mean that sun exposure is inconsequential for skin cancer: excessive UV-R exposure is indisputably a major cause of malignant melanoma. But what it does mean is that UV-R is unlikely to have created historical differences in longevity across countries via its effects on vitamin D supply and skin cancer, since evolution has traded these two factors off against each other during the selection process determining local skin color. Despite these considerations, we have nevertheless checked whether skin cancer influences the observed UV-R/income gradient documented above. As expected, it does not (see tables A9-A10 in the Supplementary Appendix).

The second type of health risk highlighted by Lucas et al. (2008) is eye disease, and, in particular, a link to a heightened incidence of cataract. The underlying evidence takes several forms. First, theoretical mechanisms connecting cataract with UV-R have been established; see, e.g., Dong et al. (2003) and the references cited therein. Second, randomized controlled animal trials have confirmed the impact of UV-R on the formation of cataract (e.g., Ayala et al. 2000). Third, epidemiological studies have demonstrated that greater exposure to UV-R produces an earlier onset of cataract in human populations (e.g., Hollows and Moran, 1981; Taylor et al., 1988; West et al., 1998). It seems fair to say that a consensus has been reached on the issue. ${ }^{17} \mathrm{UV}-\mathrm{R}$ is also suspected of influencing the incidence of two other eye diseases, namely pterygium and macular degeneration (e.g., Gallagher and Lee, 2006). It should be noted, however, that there is an ongoing debate as to which extent UV-R influences pterygium and macular degeneration. Nevertheless, at this point in time we cannot rule out that UV-R is capturing a cluster of eye diseases involving cataract, pterygium, and macular degeneration. Of these three eye diseases, cataract is worth singling out since it is a particularly important affliction measured by its prevalence; cataract is the single biggest source of preventable blindness globally (Lansingh et al., 2007). The global significance of cataract can be illustrated by the

\footnotetext{
${ }^{15}$ Malignant melanoma is by far the most dangerous type of skin cancer, but it is also the least common. There are two other types of skin cancer: basal cell cancer and squamous cell cancer. Basal cell cancer, the most common type of skin cancer, almost never spreads; squamous cell cancer is more dangerous, but not nearly as dangerous as a melanoma.

${ }^{16}$ See Diamond (2005) for a very clear exposition of these points and references to the relevant literature.

${ }^{17}$ Surveys of the literature are found in Javitt et al. (1996) and West (2007).
} 
fact that the World Health Organization specifically targeted it in the context of its "Vision 2020-the Right to Sight” campaign, which was launched in 1999 and aims to eliminate preventable blindness by the year 2020 .

Cataract is opacity of the lens of the eye, which leads to impaired vision and ultimately to blindness. ${ }^{18}$ The condition is progressive and may (after its time of onset) proceed slowly, over a time horizon of years, or rapidly, in a matter of months. In terms of risks of contracting cataract, age is the strongest factor because environmentally induced damage accumulates over time. In the end, most people experience cataract if they live long enough. Yet the timing of its onset varies considerably across individuals and countries.

This fact is well illustrated by the data depicted in Figure 3, which concerns age-specific prevalence rates of cataract at two different geographical locations: the Indian province of Punjab and Rotterdam in the Netherlands. Punjab is located in a high-UV region, whereas Rotterdam is located in a low-UV region. ${ }^{19}$ As a result, we would expect to see significant differences in cataract. This expectation is confirmed by the data depicted in Figure 3. The difference in age-specific prevalence rates is quite striking. Whereas more than half of the population that survives until the age of 80 will experience cataract in Punjab, only 2.5\% of their counterparts in the Netherlands will have a similar experience. Two things make the observed difference in prevalence rates even more remarkable. First, the survey data record cases of severe cataract, meaning that the affliction has progressed to the point where reading becomes difficult. Specifically, the prevalence rates in Punjab and Rotterdam speak to individuals with corrected visual acuity of 20/60 or worse. In practice, 20/60 visual acuity means that the individual is only able to see the first few lines on the familiar Snellen chart; it therefore implies a substantially reduced vision. ${ }^{20}$ Second, the Rotterdam survey actually considers a cluster of eye diseases, and not just cataract as in the Punjab survey. The data in the figure therefore underestimates the difference between the two locations in terms of cataract prevalence.

\footnotetext{
${ }^{18}$ In the Supplementary Appendix (Section 4) we provide vision simulations of severe cataract, which can be compared to normal vision. As should be clear, cataract is a debilitating condition that can seriously impair the vision.

${ }^{19}$ In the context of our satellite data on UV-R described above, we find that Punjab and Rotterdam are located respectively at the $60^{\text {th }}$ and $32^{\text {nd }}$ percentile in the global (grid based) distribution of UV-R.

${ }^{20}$ Ophthalmologists distinguish between "corrected" and "uncorrected" visual acuity. In the former case subjects are allowed to wear glasses (if available). Formally, a visual acuity of 20/60 means that at a 20 feet distance to the familiar test chart for eyesight, the individual can read letters that a person with 20/20 vision (the reference standard) can read at a 60 feet distance.
} 


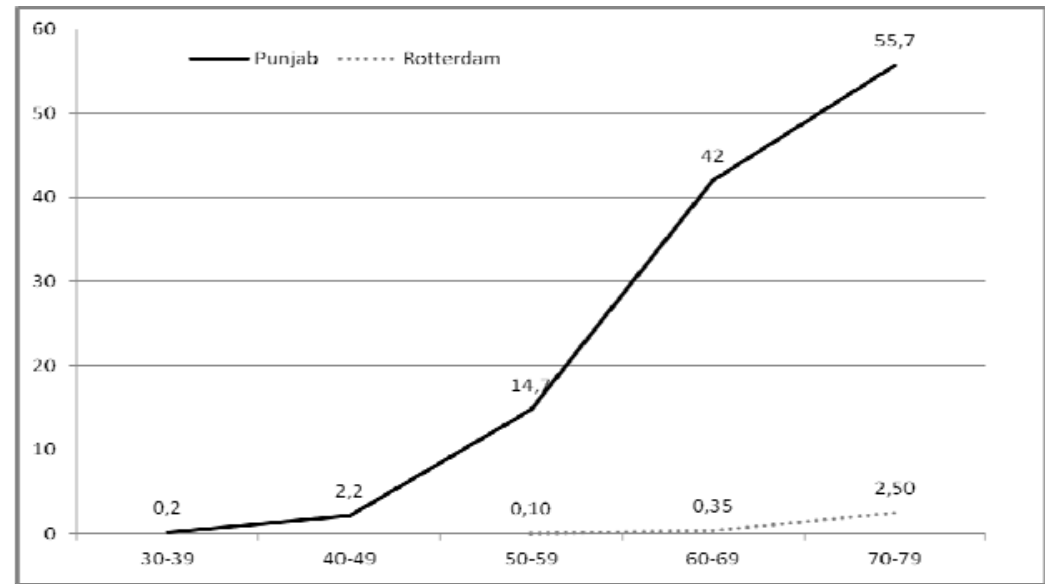

Figure 3: Age-specific cataract in Punjab (solid line) and age-specific visual impairment in Rotterdam (dotted line). Notes: Punjab data are from Chatterjee et al. (1982) and Rotterdam data are from Klaver et al. (1998). The $\mathrm{y}$-axis gives cataract prevalence in percentages, whereas the $\mathrm{x}$-axis provides the age categories.

In Section 4 of the Supplementary Appendix we employ these data to gauge the consequences of observed differences in cataract prevalence for work-life expectancy as a skilled worker. We focus on skilled labor, as eyesight arguably is paramount in human capital-intensive occupation; it is less important in unskilled occupations, where an inability to read or write need not prevent labor market participation. Assuming people work until they die (in practice until the age of 65, which was life expectancy at age 20 in Punjab at the time of the survey in 1975) and that the above data can be viewed as a reasonable indicator of the 'exit rate' out of skilled occupations (conditional on survival), we find that cataract incidence can shorten work life for skilled workers in the high-UV region (Punjab), relative to selfsame workers in the low-UV region (Rotterdam), by as much as 14 years.

In the above calculation of expected work life we assume the affliction is left untreated, which is a reasonable presumption. Historically, only very precarious forms of eye surgery were available, which undoubtedly limited its popularity. ${ }^{21}$ During the $20^{\text {th }}$ century, surgical techniques have improved enormously, but the procedure remains the work of highly trained specialists. Unfortunately, such specialists are scarce in many developing countries. In Africa, for instance, the relative number of ophthalmologists is very low: fractions as low as 1:1,000,000 inhabitants have been reported (Foster, 1991). Inevitably, this extreme supply constraint limits the possibility of cataract treatment in many poor places, even today. Surgery is also needed for the treatment of pterygium; macular degeneration, by contrast, can only be prevented. Accordingly, corrective eye surgery is unlikely to have played an

\footnotetext{
${ }^{21}$ A preferred method for dealing with cataract historically involved the displacement of the lens using a needle; a method called couching. It is noteworthy that this procedure has been practiced at least since $1000 \mathrm{BC}$ (e.g., Corser, 2000), which testifies to the fact that in spite of shorter life spans cataract was a well-known affliction requiring treatment even in antiquity.
} 
important role historically; and even during the $20^{\text {th }}$ century, access to adequate treatment is likely to have been severely limited in many places around the world. ${ }^{22}$

[Table 5 about here]

With these considerations in mind Table 5 explores whether our measure of UV-R predicts cataract incidence across countries today. ${ }^{23}$ The controls invoked, in addition to UV-R, are those featured in Tables 1 and 2. Consistent with epidemiological priors we find that UV-R is significantly correlated with cataract incidence in all specifications; typically at the $1 \%$ level of significance, though when we add all of our auxiliary controls the significance level is $5 \%$. These results provide some assurance that the UV-R variable captures disease ecology with respect to cataract.

The issue to which we turn next is why eye diseases (in general) can have an impact on comparative development, and how the impact may be of the order of magnitude recovered in our reduced-form regressions above.

\subsection{Propagation: Morbidity and the Differentiated Timing of the Take-Off}

Virtually all contributions to unified growth theory view the fertility transition as a key marker of the onset of sustained growth (for a survey of this literature, see Galor 2011). The leading theory of the onset of the fertility transition is that a gradually rising return on human capital accumulation eventually triggered a substitution of child quantity (family size) for child quality (capital investments per child) at the household level (Galor, 2011, Ch. 4). Consequently, the inherent return to skill accumulation is key to an understanding of comparative differences in the timing of the onset of the fertility transition, and thus to an understanding of cross-country income inequality (Galor, 2010). This is where eye disease may have played a role.

By lowering the expected work life over which skill investments can be recuperated, an early onset of, say, debilitating cataract will work to lower the return on human capital accumulation. As a consequence of a lower return to skills, high incidence of eye disease may serve to delay the onset of the fertility transition. If the fertility transition is an important driving force behind the take-off, an income gap emerges between countries with respectively high and low incidence of eye disease. A

\footnotetext{
${ }^{22}$ Another problem is that the quality of the treatment (if available) is often low in poor countries. For example, evaluating cataract surgery in urban India, $50 \%$ of the outcomes were classified by international experts as 'poor' or 'very poor', reflecting only limited post-operation vision (Dandona et al., 1999).

${ }^{23}$ Our incidence-of-cataract measure for each country is the number of years lost to disability (YLD) in 2004, expressed as a ratio of per 100,000 people in the population (WHO, 2008). Formally, $Y L D=I \cdot w \cdot L$, where $I$ is new incidences per year, $w$ is a weight measuring the severity of the condition, and $L$ is the average duration of the condition. The weight $w$ is the same everywhere, and so is $L$. Consequently, the cross-country variation in the variable stems from incidence, $I$.
} 
century later, such a divergence-deriving from a differential timing of the fertility transition and thus the take-off to sustained growth—should be detectable in the data. ${ }^{24}$

Is the reduction in expected work life discussed above sufficient to make the above mechanism plausible? One way to appreciate the number (i.e, 14 years) is through the lens of the study by Cervellati and Sunde (2013). The authors carefully calibrate a prototypical unified growth model, upon which they study the consequences of introducing cross-country differences in initial work life (i.e., during pre-industrial times), which is tantamount to differences in initial life expectancy in their set up. Cervellati and Sunde find that a difference in initial work life of only five years can generate a difference in the timing of the take-off to modern economic growth of nearly 150 years. Hence, a large impact of eye disease on long-run development seems plausible, even if our estimate for the reduction in expected work life in high UV-R areas were to be off by a factor of three.

To see the above argument more clearly, and with an eye to the empirical analysis to come, consider the following simple representation of the long-run growth process. ${ }^{25}$ For a country $i$ at time $t>s_{i}$, the level of (log) GDP per worker, $y_{i t}$, can be written as $y_{i t}=y_{i 0}+\left(t-s_{i}\right) \cdot g$, where $s_{i}$ is the country specific timing (year) of a take-off in growth in labor productivity, or the timing of the fertility transition as argued above. The implicit assumption is that between time zero and $s_{i}$ the economy stagnates; $y_{i 0}$ can be viewed as the subsistence level of income, or, alternatively, as the equilibrium level of income per capita prior to the take-off. For all $t>s_{i}$ the economy grows at the rate $g>0$; i.e., we assume that all countries that have taken off share the same value of $g$. Suppose that the timing of the take-off is explained by some underlying characteristic, $x_{i}$, and by other factors, $\tilde{s}_{i}$, assumed to be uncorrelated with $x_{i}$. That is, $s_{i}=\tilde{s}_{i}+\tau \cdot x_{i}$, where $\tau$ is a parameter capturing the impact of $x$ on $s$. In the argument above, $x_{i}$ would be UV-R (disease ecology); $\tilde{s}_{i}$ would capture other determinants of the timing of the fertility transition, which are unrelated to UV-R.

Now consider running a cross-country regression of $y_{i t}$ on $x_{i}$, where $y_{i t}$ is governed by the two equations above. Specifically, we estimate $y_{i t}=a+b \cdot x_{i}+\varepsilon_{i t}$. Assuming that $y_{i 0}$ is uncorrelated with $x_{i}$, the OLS estimate, $\hat{b}$, for the impact of $x$ on $y$ is given by:

$$
\widehat{b}_{t}=\frac{E\left(y_{i t} x_{i}\right)}{\sigma_{x}^{2}}=-\tau g \frac{\widetilde{N}_{t}}{N} \frac{\tilde{\sigma}_{x, t}^{2}}{\sigma_{x}^{2}}
$$

\footnotetext{
${ }^{24}$ Formal models, which predicts that variations in health status may have led to a differential timing of the take-off, are developed in Hazan and Zoabi (2006) and Cervelatti and Sunde (2013).

${ }^{25}$ This mechanical way of capturing the impact of a differential timing of the take-off on $21^{\text {st }}$ century income outcomes is inspired by Lucas (2000).
} 
where $\widetilde{N}_{t}$, a subset of $N$, is the number of countries that have managed the take-off as of time $t, \tilde{\sigma}_{x, t}^{2}$ is the variance of the characteristic $x$ across the $\widetilde{N}_{t}$ countries, and $\sigma_{x}^{2}$ is the variance of $x$ across all $N$ countries. The intuition for this result is straightforward. Since we assume that $x_{i}$ is uncorrelated with $y_{i 0}$, the OLS coefficient must be zero if no countries have managed the take-off; as seen above, $\widetilde{N}_{t}=0$ produces $\widehat{b}=0$. However, as countries start taking off in a systematic way related to $x_{i}$, a link between $y_{i t}$ and $x_{i}$ emerges. In the long run, assuming all countries have experienced their take-off, $\widehat{b}=-\tau \cdot g$; a unit change in $x$ instigates $\tau$ years of delayed take-off, which has $g$ percent as a yearly penalty in terms of labor productivity. ${ }^{26}$

The important point to note is that even if characteristic $x_{i}$ has a very limited (static) impact on the level of the growth path, measured by $y_{i 0}$ (in the example above this effect is nil), we may nevertheless find a substantial impact on $y_{i t}$ due to the influence of $x_{i}$ on the timing of the take-off.

It is possible to provide consistency checks of the proposed mechanism. The first step consists of estimating the impact of UV-R on $s_{\mathrm{i}}$, which theoretically ought to be the 'year' of the fertility transition. With an estimate for $\tau$ in hand, we may subsequently ask whether reasonable values for $g$ can account for the reduced form estimate, $\widehat{b}$. Naturally, this is only a back-of-the-envelope check, as it requires the assumption that all countries have taken off, and as it ignores convergence forces. Nevertheless, it provides a way to assess the internal consistency of any take-off account.

The mechanism we have sketched above may be (partly) responsible for the UV-R/income gradient in theory, yet the question is whether it also relevant in practice. Ultimately, the overall relevance of the mechanism hinges on a number of predictions, which should hold simultaneously. These predictions are discussed in what follows.

Prediction 1 (P1): The impact of UV-R on GDP per capita is numerically larger than the impact from UV-R on GDP per worker.

This prediction follows since the fertility transition (in theory) influences prosperity in three ways: (i) by increasing per capita resources; (ii) by instigating skill investments and thereby technological change; and (iii) by (temporarily) lowering the dependency ratio. The third source of influence is only relevant for GDP per capita. Hence, if UV-R is influencing comparative development via the fertility

\footnotetext{
${ }^{26}$ For simplicity, we are ignoring convergence, which may nonetheless be important post take-off. However, as long as income convergence is not complete, the timing of the take-off will matter to observed cross-country income differences.
} 
transition, it should — when evaluated today-exert a stronger impact on GDP per capita than GDP per worker.

P1 is evidently borne out by the data, as seen from Tables 1 and 2. The point estimate for UV-R is systematically greater (in absolute value) in the context of the GDP per capita regressions. In the rest of the paper we therefore focus on the viability of the following four predictions.

Prediction 2 (P2): The impact of UV-R on economic activity should be less important during preindustrial times.

This prediction follows since UV-R is argued to impact living standards via the fertility transition. Prior to the fertility transition one would therefore expect much less of an impact on economic activity. ${ }^{27}$

Prediction 3 (P3): UV-R should be positively correlated with the year of the fertility transition.

Prediction 4 (P4): UV-R should have no predictive power once the more proximate determinants of prosperity (the timing of the fertility transition and eye disease) are added to the reduced form specification.

Prediction 5 (P5): UV-R should be negatively correlated with human capital investments after the fertility transition.

The last prediction follows since the fertility transition is thought to be associated with a substitution of child quality for child quantity. A key dimension of child quality is investments in schooling.

\subsection{Testing the Take-off Account: Prediction 2}

Using data on GDP per capita from Maddison (2003) we re-estimate the full specificationcorresponding to the specification reported in Table 2, column 9-for the years 1820, 1900, and 1950. The results are found in Table 6, columns 4-7.

A consistent pattern emerges in the sense that starting from 1820 the size of the partial correlation rises (in absolute value) until it turns significant by 1950, where the estimate is of the same order of magnitude as those reported in Table 2. From column 7 in Table 6 we see that the estimate retains significance when we restrict the 1950-sample to countries for which GDP per capita data were also

\footnotetext{
${ }^{27}$ See the discussion above: if $\tilde{N} \approx 0$-i.e., if no countries have taken-off-then $\widehat{b} \approx 0$.
} 
available in 1900. Put differently, the significance of UV-R in 1950 is not simply a matter of more data being available. ${ }^{28}$ The change in the partial correlation between UV-R and income from 1900 to 1950 is also visually quite clear, cf. Figure 4.

[Table 6 about here]

Studying the impact of UV-R on early levels of prosperity is not without drawbacks however. To begin, there is only limited and imperfect data for GDP per capita in the $19^{\text {th }}$ century. Moreover, even if we ignore the issues of data quality and availability, the results reported in columns 4 and 5 of Table 6 do not necessarily refute a substantial influence from UV-R on historical levels of productivity. The reason is that higher levels of productivity during the period prior to the fertility transition would be converted into greater population density rather than into income gains; indeed, the Malthusian model appears appropriate for the period prior to the fertility transition (e.g., Ashraf and Galor, 2011; Clark, 2007). While the Malthusian forces that governed the growth process for most of human history had begun to evaporate during the $19^{\text {th }}$ century, one may nevertheless be concerned that income levels in 1820 is a poor indicator of productivity. This is of concern since schooling quite likely played less of role in the pre-industrial society than today. If UV-R holds a substantial impact on productivity during the pre-industrial times, one might suspect that its influence is channeled through other mechanisms than the one proposed.

A more decisive check of the historical influence of UV-R therefore involves tests of its impact on population density prior to the fertility transition. If UV-R influenced historical productivity levels, it should correlate with pre-transition population density (Ashraf and Galor, 2011). Yet, conditional on our controls, UV-R is not correlated with population density in the years 1 C.E., 1000 C.E., and 1500 C.E, respectively, as documented in Table 6, columns 1-3. This suggests that the influence from UV$\mathrm{R}$ on productivity only emerges during the post-fertility-transition era, where human capital investments take off.

\footnotetext{
${ }^{28}$ Some may ask whether Table 6 is not showing 'too much'. According to Galor and Weil (2000), the take-off was in full operation by 1900. From this perspective, it may seem puzzling that we do not detect a significant influence from UV-R as of 1900 (perhaps already as of 1820) if UV-R influences the timing of the take-off. This is not really a puzzle, however, for two reasons. First, the industrial revolution was initially confined to Europe. As a result, the continental fixed effects will pick up most of the information as long as the take-off is highly concentrated geographically. Secondly, the size of the estimate for UV-R is affected by the number of countries taking off and by the variation in UV-R across the countries that have taken off (see Section 2). Since the forerunners in the industrial revolution were a relatively small group of countries, and because Europe is a very small place climatically speaking, the variation in UV-R is relatively modest. Consequently, a modest estimate is expected prior to the 1900s. But as the industrial revolution diffused, selectively, to other continents and more countries, one would expect to see that (a) the point estimate for UV-R rises and (b) that statistical significance eventually emerges.
} 

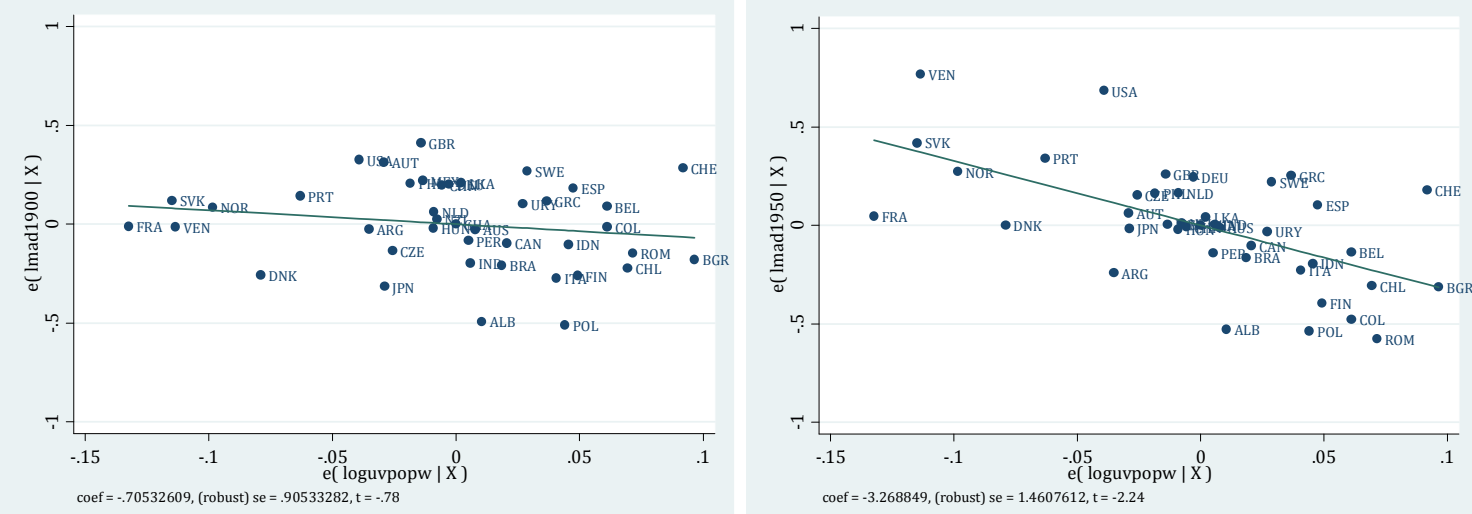

Figure 4: The partial correlation between UV-R and log GDP per capita in 1900 and 1950, respectively. Notes: The figure depicts the (partial) correlation between UV-R and GDP per capita in 1900 (left panel) and 1950 (right panel), respectively, while controlling for the influence of a full set of controls, including latitude and elevation fixed effects. The sample of countries is restricted to be the same in 1900 and 1950. Hence the slopes of the two regression lines correspond to the estimates reported in, respectively, Table 6, column 5 (for 1900) and Table 6, column 7 (for 1950).

Overall, the results reported in Table 6 suggest that UV-R's impact on current prosperity is of relatively recent origin: the negative impact emerges during the $20^{\text {th }}$ century. This supports the hypothesis that the impact of UV-R on prosperity is largely mediated through the differential timing of the take-off.

\subsection{Testing the Take-off Account: Predictions 3 and 4}

In Table 7 we test whether UV-R predicts the timing of the fertility transition, and whether the reduced-from influence from UV-R is channeled through eye disease and the fertility transition. ${ }^{29}$ In column 1 we examine the link between UV-R and the timing of the fertility transition in the 'full specification' employed in Table 1, column 8 (i.e., here we test P3). In the interest of brevity, we only report on the full specification; the full set of tests, matching the testing strategy in Tables 1 and 2, are reported in the Supplementary Appendix (Table A15). In the remaining six columns we examine whether the reduced-form link between UV-R and GDP per worker is diminished once we add the more proximate determinants of prosperity (i.e., here we test P4). In the Supplementary Appendix we provide similar results for GDP per capita (Table A16).

[Table 7 about here]

Turning to results, we start by observing that changing UV-R by one percent delays the onset of the fertility transition by roughly 33 years, which is consistent with P3. Column 2 reports the reduced-

${ }^{29}$ The data on the timing of the fertility transition derive from Reher (2004), and are described in the supplementary material. Previous studies employing Reher's data include studies by Cervelatti and Sunde (2011) and Dalgaard and Strulik (2013). 
form estimate for the UV-R gradient in the present (smaller) sample of countries for which we have data on the timing of the fertility transition; the result is similar to that reported in Table 1. Column 3 indicates that the fertility transition is significantly correlated with contemporary labor productivity; each additional year of delay is on average associated with roughly two percent lower GDP per worker in 2004. In column 4 we observe that cataract appears more prevalent in places with lower labor productivity in 2004. Column 5 introduces the three variables simultaneously, in addition to the full set of controls. The main result is that whereas the timing of the fertility transition remains significant and carries roughly the same point estimate; the point estimate for UV-R diminishes in (absolute) size and turns insignificant. To be sure, a major problem with the specification reported in column 5 is that cataract is endogenous to income, thus preventing a clean interpretation of results. Consequently, in column 6 we resort to an IV approach, instrumenting cataract prevalence by UV-R and treating the timing of the fertility transition as pre-determined. This renders the estimate for cataract insignificant, conditional on the timing of the fertility transition. While these results do not rule out a small direct impact from cataract prevalence on economic activity-conditional on the timing of the fertility transition - they are consistent with UV-R largely operating through the timing of the fertility transition (in full keeping with P4).

As a final consistency check of the mechanism, UV-R $\rightarrow$ fertility transition $\rightarrow$ current income, we gauge whether the point estimates reported in Table 7 are internally consistent. We ask whether the estimated delay in the fertility transition from UV-R can account for the reduced-form estimate of UV-R on labor productivity. To see how this check works, note that if we assume that countries grow at a rate between two and three percent per year on average post transition and that they stagnate before the transition, then the 'required' delay from one standard deviation ( 0.5 log points) increase in UV-R is, in the notation of Section 3.2, $\tau=\log (0.4 \times 1.29) / g$. The result is a required delay of between $21(\mathrm{~g}=0.02)$ and 15 years $(\mathrm{g}=0.03)$. The estimated impact from one standard deviation change in UV-R on the timing of the fertility transition is $0.5 \times 33=16.5$ years (Table 7, column 1 ). Accordingly, the estimated magnitudes match up reasonably well, once again suggesting that the reduced-form link between UV-R and labor productivity largely can be accounted for by the proposed mechanism. ${ }^{30}$

\subsection{Testing the Take-off Account: Prediction 5}

\footnotetext{
${ }^{30}$ As a consistency check of the impact of UV-R on the fertility transition we have examined the link between UV-R and fertility rates. Fertility rates with worldwide coverage are only available for a more limited period of time, which means that we have to focus on the period from 1960 onwards. Since the fertility rate declines in the aftermath of the fertility transition, one would expect to see higher fertility rates in countries exposed to greater $\mathrm{UV}-\mathrm{R}$, ceteris paribus. This is what we find, and the influence from UV-R is reduced to the point of statistical insignificance once we-in addition to the baseline controls - control for the year of the fertility transition, which itself carries a positive and statistically significant influence on average fertility rates. The results are reported in the Supplementary Appendix (Tables A18 and A20).
} 
In this context we invoke data on average years of schooling, which are available for 62 countries during the period from 1870 to the present (Morrison and Murtin, 2009). These data are described in the Supplementary Appendix. The basic specification we take to the data involves the same set of controls that we employed in Tables 1 and 2, with one addition: Average years of schooling were not zero in 1870 , for which reason the subsequent growth process is subject to mean reversion. Hence, in addition to the controls in Tables 1 and 2, we include the initial level of schooling in 1870. We find, in keeping with the proposed mechanism, that areas characterized by higher levels of UV-R experienced slower growth in years of schooling during the subsequent (roughly) 140 years. To conserve space, we have relegated the full set of estimation results to the Supplementary Appendix (Table A17).

The next issue is whether the influence from UV-R on human capital investments diminishes if we control for the timing of the fertility transition, in keeping with the proposed mechanism. It does, albeit we cannot fully exclude a small impact from UV-R on human capital investments, conditional on the timing of the fertility transition, as UV-R at times remains (marginally) significant. The estimation results are found in the Supplementary Appendix (Table A19).

\subsection{Within-Country Analysis: China and US}

A drawback of the tests conducted in Sections 3.3-3.4 is that they only rely on country-level data. Unfortunately, symmetrical tests using pixel-level data are not feasible due to the lack of data on the timing of the fertility transition. But indirect evidence can be brought to bear.

The United States is one of the so-called forerunners in terms of the fertility transition (Reher, 2004). As observed in the Section 1, Bleakley and Lange (2009) and Hansen et al. (2014) document a strong link between human capital accumulation and fertility. If UV-R, as hypothesized above, were indeed a determinant of the perceived return to schooling, one would expect to see a UV-R/income gradient within the US.

A country worth contrasting with the US is China. According to demographers, China went through the fertility transition in the 1970s (Reher, 2004). Unlike the US, however, the Chinese experience was heavily influenced by government policy. In particular, the 'later, longer, fewer' policy of 1971which encouraged people to have children later in life, increase birth spacing, and thus simply have fewer children - and the one-child policy, which was announced in 1979, are often identified by demographers to have been important drivers (e.g., Coale, 1984; Bongaarts and Greenhalgh, 1985; Xizhe, 1989). The work by Li and Zhang (2007) supports this assessment. The authors observe that the one-child policy was subject to an important qualification: it only applied to Han Chinese, whereas ethnic minorities did not have to abide by the policy. Consequently, if the policy was in fact 
effective, the minority share of regional populations should be a good predictor of cross-regional fertility. Specifically, in areas with more ethnic minorities fertility should be higher, insofar as the policy was binding. This does in fact seem to be the case. Li and Zhang further document that the fertility transition importantly stimulated economic growth in China. For present purposes, however, the main point is that the measures of population control enacted by the Chinese government were pervasive, apparently effective, and thus unlikely to be correlated with UV-R within China. We therefore expect that UV-R is much weaker correlated with regional levels of development within China than what is the case within the US, given the proposed mechanism linking UV-R to prosperity.

In Table 8 we report the results from estimating the impact of UV-R on regional economic activity within China and the US. As the indicator for economic activity we employ nightlights. The model is estimated at all three levels of aggregation (i.e., 1x1, 2x2, and $4 \times 4$ resolution) and we estimate it with the same controls as those invoked in the context of Tables 3 and 4, except that we obviously have no need for country fixed effects. Hence in the first two columns we compare China and the US at the $1 x 1$ level, and without any fixed effects; the subsequent two columns invoke language fixed effects. This procedure is repeated at the $2 \times 2$ and $4 \times 4$ level.

[Table 8 about here]

Our findings are quite striking. Whereas the negative link between UV-R and regional development is strongly borne out by the US data, UV-R and economic activity is virtually uncorrelated (conditional on controls) within China. Consistent with priors, it seems that the mechanism detected at the country level has not been operative within China, most likely because the fertility transition was largely driven by government policy. In contrast, and consistent with the analysis in Bleakley and Lange (2009) and Hansen et al. (2014) for the US, UV-R is strongly and negatively correlated with economic activity within the US. This is of course fully consistent with an impact of UV-R on the perceived return to skill investments, which in turn has been important in generating a differential timing of the fertility transition, ultimately leaving its mark on contemporary comparative development within the US.

\section{Conclusion}

The present study has documented a remarkably robust correlation between the intensity of UV radiation and contemporary economic development. It holds both across and within countries; and it is robust to a demanding set of auxiliary controls, including factors determining UV-R such as (absolute) latitude and topography. 
To interpret this correlation, we propose a mechanism that links UV-R to economic development via the timing of the fertility transition and subsequent child quality investments. The hypothesis is that UV-R - by having an epidemiologically well-established impact on the incidence of debilitating eye disease-may have lowered the perceived return to skill formation in places where people historically were exposed to relatively high levels of UV-R. According to a well-established body of theoretical work, this should instigate a delayed fertility transition in high UV-R regions, causing less subsequent skill investments and thereby comparatively low levels of income per capita today.

We submit this mechanism to a demanding set of checks, which all support its viability. Places with higher UV-R are characterized by a greater prevalence of potentially debilitating eye diseases, a delayed fertility transition, and less skill investments during the post 1870 period. The influence from UV-R on income, fertility and skill investments is greatly diminished (or simply disappears) once we control for the timing of the fertility transition, and individual estimates obtained in independent regressions appear internally consistent. While we cannot rule out that the link between UV-R and contemporary development has other explanations than the one examined above, a compelling case can be made that a delay in the timing of the fertility transition, and thus in the take-off to sustained economic growth, should be an important facet of any explanation.

\section{REFERENCES}

Acemoglu, Daron. 2008. Introduction to Modern Economic Growth. Princeton: Princeton University Press.

Acemoglu, Daron, and Simon Johnson. 2007. "Disease and development: the effect of life expectancy on economic growth.” Journal of Political Economy, 115(6): 925-985.

Aghion, Philippe, Peter Howitt, and Fabrice Murtin. 2010. "The relationship between health and growth: when Lucas meets Nelson-Phelps.” NBER working Paper No. 15813.

Altonji, Joseph G., Todd E. Elder, and Christopher R. Taber. 2005. "Selection on Observed and Unobserved Variables: Assessing the Effectiveness of Catholic Schools.” Journal of Political Economy, 113(1): 151-184.

Andersen, Thomas B., and Carl-Johan Dalgaard. 2011. "Flows of People, Flows of Ideas and the Inequality of Nations.” Journal of Economic Growth, 16(1): 1-32.

Angeles, Luis. 2010. "Demographic transitions: Analyzing the effects of mortality on fertility." Journal of Population Economics, 23: 99-120.

Ashraf, Quamrul, and Oded Galor. 2011. "Dynamics and Stagnation in the Malthusian Epoch.” American Economic Review, 101(5): 2003-2041.

Ashraf, Quamrul, and Oded Galor. 2013. The "Out-of-Africa” Hypothesis, Human Genetic Diversity, and Comparative Economic Development. American Economic Review, 103: 1-46.

Ashraf, Quamrul, Ashley Lester, and David Weil. 2008. "When Does Improving Health Raise GDP?” NBER Macroeconomics Annual, 23(1): 157-204.

Ayala, Marcelo N., Ralph Michael, and Per G. Söderberg. 2000. "Influence of exposure time for UV radiation-induced cataract.” Investigative ophthalmology \& visual science, 41(11): 353943. 
Becker, Sascha O., and Ludger Woesmann. 2009. "Was Weber Wrong? A Human Capital Theory of the Protestant Reformation.” Quarterly Journal of Economics, 124(2): 531-596.

Becker, Sascha O., Francesco Cinnirella, and Ludger Woesmann. 2010. "The trade-off between fertility and education: evidence from before the demographic transition.” Journal of Economic Growth, 15 (3): 177-204.

Bleakley, Hoyt. 2007. "Disease and Development: Evidence from Hookworm Eradication in the American South.” Quarterly Journal of Economics, 122 (1): 73-117.

Bleakley, Hoyt and Fabian Lange, 2009. Chronic disease burden and the interaction of education, fertility and growth. Review of Economics and Statistics 91, 53-65.

Bongaarts, John, and Susan Greenhalgh. 1985. "An Alternative to the One-Child Policy in China." Population and Development Review, 11(4): 585-617

Calbo, Josep, David Pages, and Josep-Abel Gonzáles. 2005. "Empirical studies of cloud effects on UV radiation: A review.” Reviews of Geophysics, 43/2, 1-28

Cervellati, Matteo, and Uwe Sunde. 2011. "Life Expectancy and Economic Growth: The Role of the Demographic Transition.” Journal of Economic Growth, 16 (2): 99-133.

Cervellati, Matteo, and Uwe Sunde. 2013. The Economic and Demographic Transition, Mortality, and Comparative Development. American Economic Journal: Macroeconomics, forthcoming

Chatterjee, Arin, Roy C. Milton, and Sydney Thyle. 1982. "Prevalence and aetiology of cataract in Punjab.” British Journal of Ophthalmology, 66: 35-42.

Clark, Gregory. 2007. A Farewell to Alms: A Brief Economic History of the World. Princeton University Press.

Coale, Ansley. 1984. "Rapid Population Change in China, 1952-1982." Washington, D.C., Committee on Population and Demography, Report No. 27, National Research Council, National Academy Press.

Cockell, Charles S., and Gerda Horneck. 2001. "The History of the UV Radiation Climate of the Earth - Theoretical and Space-based Observations.” Photochemistry and Photobiology, 73(4): 447-51.

Corser, Noel. 2000. "Couching for Cataract: Its Rise and Fall.” The Proceedings of the $9^{\text {th }}$ Annual History of Medicine Days, edited by W. A. Whitelaw, pp. 35-41.

Dandona, Lalit, Rakhi Dandona, Thomas J. Naduvilath, Catherine A. McCarty, Partha Mandal, M. Srinivas, Ashok Nanda, and Gullapalli N. Rao. 1999. "Population-based assessment of the outcome of cataract surgery in an urban population in Southern India." American Journal of Ophthalmology 127 (6): 650-658.

Dalgaard, Carl-Johan, and Holger Strulik. 2013. "The History Augmented Solow Model." European Economic Review 63 134-49.

Deaton, Angus. 2010. "Instruments, Randomization, and Learning about Development." Journal of Economic Literature 48, 424-55.

Diamond, Jared. 1997. Guns, Germs and Steel. New York: W.W. Norton.

Diamond, Jared. 2005. "Evolutionary biology: Geography and skin color.” Nature, 435: 283-284.

Dong, Xiuqin , Marcelo Ayala, Stefan Löfgren, and Per G. Söderberg. 2003. "Ultraviolet Radiation-Induced Cataract: Age and Maximum Acceptable Dose.” Investigative Ophthalmological and Visual Science, 44(3): 1150-54.

Feyrer, james, and Bruce Sacerdote. 2009. "Colonialism and Modern Income-Islands as Natural Experiments.” Review of Economics and Statistics, 91(2): 245-262.

Foster Allen. 1991. "Who will operate on Africa's 3 million curably blind people?" Lancet, 337(8752): 1267-1269.

Frankel, Jeffrey A., and David Romer. 1999. “Does trade cause growth?” American Economic Review, 89(June): 379-399. 
Gallagher, Richard P., and Tim K. Lee. 2006. "Adverse effects of ultraviolet radiation: A brief review.” Progress in Biophysics and Molecular Biology, 92(1): 119-131

Gallup, John L., and Jeffrey D. Sachs. 2000. Agriculture, climate, and technology: why are the tropics falling behind? American Journal of Agricultural Economics, 82: 731-737.

Gallup, John L., and Jeffrey D. Sachs. 2001. “The economic burden of malaria.” American Journal of Tropical Medicine and Hygiene, 64(1, 2)S: 85-96

Galor, Oded. 2010. "2008 Lawrence R. Klein Lecture - Comparative Economic Development: Insights from Unified Growth Theory.” International Economic Review, 51(1): 1-44.

Galor, Oded. 2011. Unified Growth Theory. Princeton: Princeton University Press.

Galor, Oded, and David N. Weil. 2000. "Population, technology and growth: From Malthusian stagnation to the demographic transition and beyond." American Economic Review 90(4): 806828.

Galor, Oded, and Omar Moav. 2002. "Natural selection and the origin of economic growth." Quarterly Journal of Economics, 117(4): 1133-1191.

Gennaioli Nicola, Rafael La Porta, Florencio Lopez-de-Silanes, and Andrei Shleifer, 2013. “Human Capital and Regional Development.” Quarterly Journal of Economics, 128: 105-164.

Glaeser, Edward L., Rafael La Porta, Florencio Lopez-de-Silanes, and Andrei Shleifer. 2004. "Do Institutions Cause Growth?” Journal of Economic Growth, 9: 271-303

Hansen, Gary D., and Edward C. Prescott. 2002. "Malthus to Solow." American Economic Review, 92(4): 1205-1217.

Hansen, Casper W., Peter Sandholt Jensen, and Lars Lønstrup. 2014. “The Fertility Transition in the US: Schooling or Income?” Economics Working Papers 2014-02, School of Economics ad Management, University of Aarhus

Hazan, Moshe. 2009. "Longevity and Lifetime Labor Supply: Evidence and Implications" Econometrica, 77: 1829-1863.

Hazan, Moshe, and Hosny Zoabi. 2006. "Does Longevity Cause Growth? A Theoretical Critique.” Journal of Economic Growth 11(4): 363-76.

Henderson, Vernon, Adam Storeygard and David Weil. 2012. "Measuring Economic Growth From Outer Space”. Forthcoming: American Economic Review, 102(2): 994-1028.

Herzer, Dierk, Holger Strulik, and Sebastian Vollmer. 2012. "The long-run determinants of fertility: one century of demographic change 1900-1999.” Journal of Economic Growth, 17(4): 357-385

Hollows, Fred, and David Moran. 1981. "Cataract-the ultraviolet risk factor." The Lancet, 318(8258): 1249-1250.

Kalemli-Ozcan, Sebnem, and Belgi Turan. 2011.” HIV and Fertility Revisited.” Journal of Development Economics, 96(1): 61-65

Klaver, Caroline C., Roger C. Wolfs, Johannes R. Vingerling, Albert Hofman, and Paulus de Jong. 1998. "Age-Specific Prevalence and Causes of Blindness and Visual Impairment in an Older Population.” Archives of Ophthalmology, 116(May): 653-658

Li, Hongbin, and Junsen Zhang, 2007. "Do high birth rates hamper economic growth?" Review of Economics and Statistics, 89: 110-117.

Javitt, Jonathan C., Fang Wang, and Sheila K. West. 1996. "Blindness due to Cataract: Epidemiology and Prevention.” Annual Reviews of Public Health, 17: 159-77

Lansingh, Van C., Marissa J. Carter, and Marion Martens. 2007. "Global Cost-effectiveness of Cataract Surgery.” Ophthalmology, 114(9): 1670-1678.

Lorentzen, Peter, John McMillan, and Romain Wacziarg. 2008. "Death and development." Journal of Economic Growth, 13(2): 81-124. 
Lucas, Robert E. Jr. 2000. "Some Macroeconomics for the 21st Century." Journal of Economic Perspectives, 14(1): 159-68.

Lucas, Robert E. Jr. 2002. Lectures on Economic Growth. Cambridge Massachusetts: Harvard University Press.

Lucas, Robyn M., Anthony J. McMichael, Bruce K. Armstrong and Wayne T. Smith. 2008.

Estimating the global disease burden due to ultraviolet radiation exposure. International journal of epidemiology 37 (3), 654-67.

Maddison, Angus. 2003. The World Economy: Historical Statistics. Paris, France: OECD.

Masters, William, and Margaret McMillan. 2001. "Climate and Scale in Economic Growth." Journal of Economic Growth (6): 167-86.

Michalopoulos, Stelios, and Elias Papaioannou. 2013. "Pre-colonial ethnic institutions and contemporary African Development.” Econometrica 81: 113-52.

Morrison, Christian, and Fabrice Murtin. 2009. “A century of education.” Journal of Human Capital, 3(1): 1-42.

Murtin, Fabrice. 2013. "Long-term Determinants of the Demographic Transition, 1870-2000." Review of Economics and Statistics, 95(2): 617-631.

Nunn, Nathan. 2008. "The Long-Term Effects of Africa's Slave Trades." Quarterly Journal of Economics, 123(1): 139-176.

Nunn, Nathan, 2014. Historical Development. In (eds.) Philipe Aghion and Steven Durlauf: "Handbook of Economic Growth" (2 ${ }^{\text {nd }}$ edition), Chapter 7, pp. 347-402, Elsevier, North Holland.

Olsson, Ola, and Douglas A. Hibbs. 2005. "Biogeography and Long-Run Economic Development.” European Economic Review, 49(4): 909-938.

Olsson, Ola, and Gustav Hansson. 2011. "Country Size and the Rule of Law: Resuscitating Montesquieu.” European Economic Review, 55(5): 613-629

Oster, Emily. 2015. "Unobservable Selection and Coefficient Stability: Theory and Evidence." Manuscript, Brown University

Reher, David S. 2004. "The demographic transition revisited as a global process.” Population Space and Place, 10, 19-42.

Tabellini, Guido. 2010. "Culture and Institutions: Economic Development in the Regions of Europe.” Journal of the European Economic Association, 8: 677-716.

Taylor, Hugh R., Sheila K. West, Frank S. Rosenthal, Beatriz Muñoz, Henry S. Newland, Helen Abbey, and Edward A. Emmett. 1988. "Effect of ultraviolet radiation on cataract formation." New England Journal of Medicine, 319: 1429-1433.

Weil, David N. 2007. "Accounting for The Effect of Health on Economic Growth." Quarterly Journal of Economics, 122(3): 1265-1306.

West, Sheila K. 2007. "Epidemiology of Cataract: Accomplishments over 25 years and Future Directions.” Ophthalmic Epidemiology, 14(4): 173-178.

West Sheila K., Donald D. Duncan, Beatrice Muñoz, Gary S. Rubin, Linda P. Fried, Karen Bandeen-Roche, and Oliver D. Schein. 1998. "Sunlight exposure and risk of lens opacities in a population-based study: The Salisbury Eye Evaluation Project.” Journal of the American Medical Association, 280(8): 714-718.

World Health Organization. 2008. "The global burden of disease: 2004 update". http://www.who.int/entity/healthinfo/global_burden_disease/GBD_report_2004update_full.pdf.

Xizhe, Peng. 1989. "Major Determinants of China's Fertility Transition.” China Quarterly, 117: 1-37.

Young, Alwyn. 2005. "The Gift of the Dying: The Tragedy of AIDS and the Welfare of Future African Generations.” Quarterly Journal of Economics, 120(2): 423-466. 
Table 1

Real GDP per worker and exposure to UV radiation

1

Dependent variable:

23

3

4

5

6

7

8

9

(log) Real GDP per worker, 2004

\begin{tabular}{|c|c|c|c|c|c|c|c|c|c|}
\hline (log) UV & $\begin{array}{c}-1.32 * * * \\
{[0.12]}\end{array}$ & $\begin{array}{c}-1.06 * * * \\
{[0.27]}\end{array}$ & $\begin{array}{c}-1.10^{* * *} \\
{[0.20]}\end{array}$ & $\begin{array}{c}-1.35^{* *} \\
{[0.55]}\end{array}$ & $\begin{array}{c}-1.55^{* * *} \\
{[0.25]}\end{array}$ & $\begin{array}{c}-1.36 * * * \\
{[0.12]}\end{array}$ & $\begin{array}{c}-1.65^{* * *} \\
{[0.19]}\end{array}$ & $\begin{array}{c}-1.52^{* * *} \\
{[0.42]}\end{array}$ & $\begin{array}{c}-1.46^{* *} \\
{[0.61]}\end{array}$ \\
\hline Observations & 145 & 145 & 145 & 145 & 145 & 145 & 145 & 145 & 145 \\
\hline R-squared & 0.37 & 0.50 & 0.39 & 0.54 & 0.37 & 0.50 & 0.43 & 0.67 & 0.72 \\
\hline Partial R-squared & 0.37 & 0.10 & 0.15 & 0.04 & 0.16 & 0.39 & 0.21 & 0.07 & 0.05 \\
\hline Additional controls & - & Continent FEs & $\begin{array}{l}\text { Latitude, elevation } \\
\quad \text { (levels) }\end{array}$ & $\begin{array}{l}\text { Latitude, elevation } \\
\text { (FEs) }\end{array}$ & $\begin{array}{l}\text { Precipitation, } \\
\text { temperature }\end{array}$ & $\begin{array}{l}\text { Distance to ocean, } \\
\text { rivers, area, timing } \\
\text { Neolithic revolution }\end{array}$ & $\begin{array}{l}\text { Agricultural } \\
\text { suitability, tropical } \\
\text { area, frost }\end{array}$ & $\begin{array}{l}\text { All controls (with } \\
\text { latitude and } \\
\text { elevation levels) }\end{array}$ & $\begin{array}{l}\text { All controls (with } \\
\text { latitude and } \\
\text { elevation FEs) }\end{array}$ \\
\hline Number of additional controls & - & 4 & 2 & 14 & 2 & 4 & 3 & 15 & 27 \\
\hline
\end{tabular}

Joint significance of the additional control variables (p-values for the HO: all regressors [except UV] are jointly insignificant):

\section{Continent FEs}

Latitude, elevation (levels)

Latitude, elevation (FEs)

Precipitation, temperature

Distance to ocean, rivers, area, timing Neolithic revolution

Agricultural suitability, tropical area, frost

All controls (with latitude and elevation levels)

All controls (with latitude and elevation FEs)
0.00

0.16

0.00

0.00

0.00

0.00

0.00

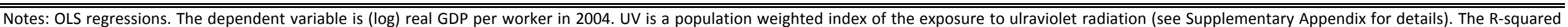

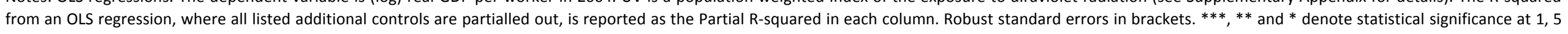
and $10 \%$ level, respectively. All regressions include a constant term. All variables described in detail in the Supplementary Appendix. 
Table 2

Real GDP per capita and exposure to UV radiation

12

4

5

6

7

8

Dependent variable:

(log) Real GDP per capita, 2004

\begin{tabular}{|c|c|c|c|c|c|c|c|c|c|}
\hline (log) UV & $\begin{array}{c}-1.47^{* * *} \\
{[0.13]}\end{array}$ & $\begin{array}{c}-1.18^{* * *} \\
{[0.28]}\end{array}$ & $\begin{array}{c}-1.35^{* * *} \\
{[0.20]}\end{array}$ & $\begin{array}{c}-1.82^{* * *} \\
{[0.61]}\end{array}$ & $\begin{array}{c}-1.75^{* * *} \\
{[0.27]}\end{array}$ & $\begin{array}{c}-1.55^{* * *} \\
{[0.13]}\end{array}$ & $\begin{array}{c}-1.95^{* * *} \\
{[0.22]}\end{array}$ & $\begin{array}{c}-1.64^{* * *} \\
{[0.46]}\end{array}$ & $\begin{array}{c}-1.70^{* * *} \\
{[0.62]}\end{array}$ \\
\hline Observations & 147 & 147 & 147 & 147 & 147 & 147 & 147 & 147 & 147 \\
\hline R-squared & 0.39 & 0.52 & 0.40 & 0.55 & 0.41 & 0.50 & 0.44 & 0.67 & 0.73 \\
\hline Partial R-squared & 0.39 & 0.12 & 0.20 & 0.07 & 0.19 & 0.43 & 0.25 & 0.08 & 0.06 \\
\hline Additional controls & - & Continent FEs & $\begin{array}{l}\text { Latitude, elevation } \\
\quad \text { (levels) }\end{array}$ & $\begin{array}{l}\text { Latitude, elevation } \\
\text { (FEs) }\end{array}$ & $\begin{array}{l}\text { Precipitation, } \\
\text { temperature }\end{array}$ & $\begin{array}{l}\text { Distance to ocean, } \\
\text { rivers, area, timing } \\
\text { Neolithic revolution }\end{array}$ & $\begin{array}{l}\text { Agricultural } \\
\text { suitability, tropical } \\
\text { area, frost }\end{array}$ & $\begin{array}{l}\text { All controls (with } \\
\text { latitude and } \\
\text { elevation levels) }\end{array}$ & $\begin{array}{l}\text { All controls (with } \\
\text { latitude and } \\
\text { elevation FEs) }\end{array}$ \\
\hline Number of additional controls & - & 4 & 2 & 14 & 2 & 4 & 3 & 15 & 27 \\
\hline
\end{tabular}

Joint significance of the additional control variables (p-values for the HO: all regressors [except UV] are jointly insignificant):

\section{Continent FEs}

Latitude, elevation (levels)

Latitude, elevation (FEs)

Precipitation, temperature

Distance to ocean, rivers, area, timing Neolithic revolution

Agricultural suitability, tropical area, frost

All controls (with latitude and elevation levels)

All controls (with latitude and elevation FEs)
0.00

0.46

0.00

0.30

0.00

0.01

0.00

0.00

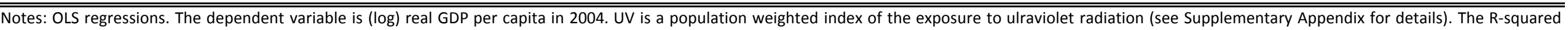

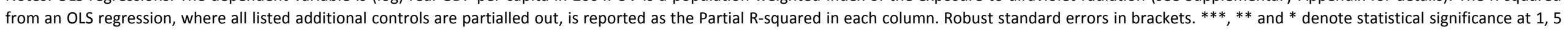
and $10 \%$ level, respectively. All regressions include a constant term. All variables described in detail in the Supplementary Appendix. 
Dependent variable:

(log) Real GDP per capita, 2005
$1 \times 1$

2
$2 \times 2$

$5 \quad 6$

$\overline{4} 5$

$4 \times 4$

$4 \times 4$

$\longrightarrow$

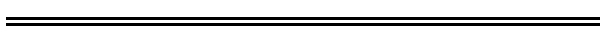

(log) UV

1

3

(2)

$-0.63 * * *$

$-0.18^{* * *}$

$-0.18 * * *$

$-0.63^{* * *}$

$-0.19 * * *$

20

$-0.63$

$[0.21]$

$\begin{array}{ll}{[0.06]} & {[0.05]} \\ (0.03) & (0.04)\end{array}$

[0.21]

[0.06]

$-0.19 * * *$
$[0.05]$

(0.11)

$(0.05)$

$(0.06)$

$-0.63 * * *$

\begin{tabular}{ccc}
{$[0.20]$} & {$[0.06]$} & {$[0.07]$} \\
$(0.17)$ & $(0.07)$ & $(0.08)$ \\
& & \\
\hline & & \\
1,929 & 1,929 & 1,929 \\
0.52 & 0.95 & 0.95 \\
0.04 & 0.02 & 0.03 \\
& & \\
8 & 8 & 8 \\
- & Country & Language \\
& 158 & 413 \\
Country & Country & Language
\end{tabular}

$-0.20 * * *$

[0.06]

$-0.25 * * *$

Observations

Observations

$\begin{array}{ccc}17,074 & 17,074 & 17,074 \\ 0.50 & 0.92 & 0.92 \\ 0.04 & 0.01 & 0.01 \\ & & \\ 8 & 8 & 8 \\ - & \text { Country } & \text { Language } \\ - & 158 & 1,176 \\ \text { Country } & \text { Country } & \text { Language }\end{array}$

5,389
0.52

5,389

$0.04 \quad 0.93$

All controls (with latitude and elevation levels)

Additional controls

Number of additional controls

Fixed effects

Number of fixed effects

Std errors clustered by:

Country

$\begin{array}{ccc}8 & 8 & 8 \\ - & \text { Country } & \text { Language } \\ & 158 & 814 \\ \text { Country } & \text { Country } & \text { Language }\end{array}$

5,389
0.94
0.01
evation leve
8
Language
814
Language

Joint significance of the additional control variables (p-values for the HO: all regressors [except UV] are jointly insignificant):

$\begin{array}{lllllllll}\text { All controls } & \\ \text { (with latitude and elevation levels) } & 0.00 & 0.00 & 0.00 & 0.00 & 0.00 & 0.00 & 0.00 & 0.00\end{array}$

\footnotetext{
Notes: OLS regressions. The dependent variable is (log) real GDP per capita in 2005. Each observation is for a geographic pixel of 1x1, 2x2, or 4x4 degrees of latitude and longitude, respectively. GDP per capita constructed with data from Yale GECON 3.4 database. UV is an index of the exposure to ulraviolet radiation (see Supplementary Appendix for details). For the case of $2 \times 2$ and $4 \times 4$ aggreagted pixel analysis, the UV index is weighted by the proportion of total population in each unit of aggregation. The Rsquared from an OLS regression, where all listed additional controls are partialled out, is reported as the Partial R-squared in each column. Robust standard errors in brackets. All controls are: (log) latitude, (log) elevation ('000 m), (average 1990-2008) temperature, (average 1990-2008) precipitation, (log) country area (sq km), distance to ocean (km), distance to major rivers $(\mathrm{km})$, and distance to the capital of the country $(\mathrm{km})$. Language FEs computed from the World Language Mapping System. Standard errors clustered by country or predominant language area reported in brackets. Conley standard errors, robust to spatial autocorrelation, are reported in parentheses. ${ }^{* *}, * *$ and $*$ denote statistical significance at 1, 5 and $10 \%$ level, respectively, based on the clustered standard errors. All regressions include a constant term. All variables described in detail in the Supplementary Appendix.
} 
Table 4

Intensity of lights by night and exposure to UV radiation: Pixel level analysis

Dependent variable:

Granularity:



(log) Intensity of lights by night, 2004

\begin{tabular}{|c|c|c|c|c|c|c|c|c|c|}
\hline \multirow{3}{*}{ Granularity: } & & & & & & & & & \\
\hline & \multicolumn{3}{|c|}{$1 \times 1$} & \multicolumn{3}{|c|}{$2 \times 2$} & \multicolumn{3}{|c|}{$4 \times 4$} \\
\hline & 1 & 2 & 3 & 4 & 5 & 6 & 7 & 8 & 9 \\
\hline (log) UV & $\begin{array}{c}-0.41 * * * \\
{[0.06]} \\
(0.03)\end{array}$ & $\begin{array}{c}-0.25^{* * *} \\
{[0.09]} \\
(0.03)\end{array}$ & $\begin{array}{c}-0.23 * * * \\
{[0.09]} \\
(0.03)\end{array}$ & $\begin{array}{c}-0.46 * * * \\
{[0.04]} \\
(0.04)\end{array}$ & $\begin{array}{c}-0.29 * * * \\
{[0.09]} \\
(0.05)\end{array}$ & $\begin{array}{c}-0.28^{* * *} \\
{[0.09]} \\
(0.05)\end{array}$ & $\begin{array}{c}-0.44 * * * \\
{[0.05]} \\
(0.08)\end{array}$ & $\begin{array}{c}-0.29 * * * \\
{[0.10]} \\
(0.07)\end{array}$ & $\begin{array}{c}-0.30 * * * \\
{[0.10]} \\
(0.08)\end{array}$ \\
\hline Observations & 18,245 & 18,245 & 18,245 & 5,652 & 5,652 & 5,652 & 2,036 & 2,036 & 2,036 \\
\hline R-squared & 0.31 & 0.40 & 0.46 & 0.40 & 0.54 & 0.60 & 0.40 & 0.63 & 0.67 \\
\hline Partial R-squared & 0.04 & 0.01 & 0.01 & 0.08 & 0.02 & 0.02 & 0.07 & 0.03 & 0.02 \\
\hline Additional controls & \multicolumn{9}{|c|}{ All controls (with latitude and elevation levels) } \\
\hline Number of additional controls & 8 & 8 & 8 & 8 & 8 & 8 & 8 & 8 & 8 \\
\hline Fixed effects & - & Country & Language & - & Country & Language & - & Country & Language \\
\hline Number of fixed effects & - & 181 & 1,228 & & 181 & 858 & & 181 & 444 \\
\hline Std errors clustered by: & Country & Country & Language & Country & Country & Language & Country & Country & Language \\
\hline
\end{tabular}

Joint significance of the additional control variables (p-values for the HO: all regressors [except UV] are jointly insignificant):
All controls
(with latitude and elevation levels)
0.00
$0.01 \quad 0.00$
0.00
0.03
0.00
0.00
0.01
0.00

Notes: OLS regressions. The dependent variable is the average intensity of lights at night in 2004. Each observation is for a geographic pixel of 1x1, 2x2, or 4x4 degrees of latitude and longitude, respectively. UV is an index of the exposure to ulraviolet radiation (see Supplementary Appendix for details). For the case of $2 \times 2$ and $4 \times 4$ aggreagted pixel analysis, the UV index is weighted by the proportion of total population in each unit of aggregation. The R-squared from an OLS regression, where all listed additional controls are partialled out, is reported as the Partial R-squared in each column. Robust standard errors in brackets. All controls are: (log) latitude, (log) elevation ('000 m), (average 1990-2008) temperature, (average 1990-2008) precipitation, (log) country area ( $\mathrm{sq} \mathrm{km})$, distance to ocean ( $\mathrm{km})$, distance to major rivers (km), and distance to the capital of the country ( $\mathrm{km}$ ). Language FEs computed from the World Language Mapping System. Standard errors clustered by country or predominant language area reported in brackets. Conley standard errors, robust to spatial autocorrelation, are reported in parentheses. ${ }^{* * *},{ }^{* *}$ and ${ }^{*}$ denote statistical significance at 1,5 and $10 \%$ level, respectively, based on the clustered standard errors. All regressions include a constant term. All variables described in detail in the Supplementary Appendix. 
Table 5

Cataract prevalence and exposure to UV

1

5

9

Dependent variable:

(log) Cataract prevalence, 2004

\begin{tabular}{|c|c|c|c|c|c|c|c|c|c|}
\hline$(\log )$ UV & $\begin{array}{c}2.37^{* * *} \\
{[0.14]}\end{array}$ & $\begin{array}{c}1.54 * * * \\
{[0.30]}\end{array}$ & $\begin{array}{c}2.40 * * * \\
{[0.19]}\end{array}$ & $\begin{array}{c}2.50 * * * \\
{[0.82]}\end{array}$ & $\begin{array}{c}2.03 * * * \\
{[0.28]}\end{array}$ & $\begin{array}{c}2.46 * * * \\
{[0.17]}\end{array}$ & $\begin{array}{c}2.29 * * * \\
{[0.25]}\end{array}$ & $\begin{array}{c}1.48 * * * \\
{[0.46]}\end{array}$ & $\begin{array}{c}2.11 * * * \\
{[0.58]}\end{array}$ \\
\hline Observations & 147 & 147 & 147 & 147 & 147 & 147 & 147 & 147 & 147 \\
\hline R-squared & 0.62 & 0.79 & 0.64 & 0.68 & 0.67 & 0.66 & 0.66 & 0.82 & 0.84 \\
\hline Partial R-squared & 0.62 & 0.24 & 0.44 & 0.10 & 0.25 & 0.62 & 0.32 & 0.07 & 0.09 \\
\hline Additional controls & - & Continent FEs & $\begin{array}{l}\text { Latitude, } \\
\text { elevation (levels) }\end{array}$ & $\begin{array}{c}\text { Latitude, } \\
\text { elevation (FEs) }\end{array}$ & $\begin{array}{l}\text { Precipitation, } \\
\text { temperature }\end{array}$ & $\begin{array}{l}\text { Distance to ocean, } \\
\text { rivers, area, } \\
\text { timing Neolithic } \\
\text { revolution }\end{array}$ & $\begin{array}{l}\text { Agricultural } \\
\text { suitability, tropical } \\
\text { area, frost }\end{array}$ & $\begin{array}{l}\text { All controls (with } \\
\text { latitude and } \\
\text { elevation levels) }\end{array}$ & $\begin{array}{l}\text { All controls (with } \\
\text { latitude and } \\
\text { elevation FEs) }\end{array}$ \\
\hline Number of additional controls & - & 4 & 2 & 14 & 2 & 4 & 3 & 15 & 27 \\
\hline
\end{tabular}

Joint significance of the additional control variables (p-values for the HO: all regressors [except UV] are jointly insignificant):

Continent FEs

Latitude, elevation (levels)

Latitude, elevation (FEs)

Precipitation, temperature

Distance to ocean, rivers, area, timing Neolithic revolution

Agricultural suitability, tropical area, frost

All controls (with latitude and elevation levels)

All controls (with latitude and elevation FEs)
0.00

0.01

0.01

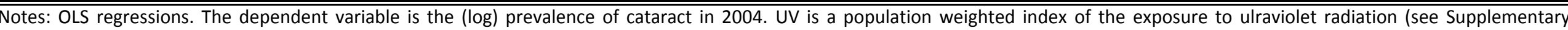

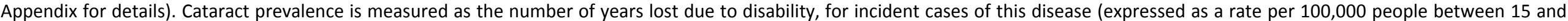

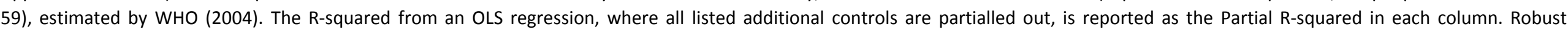

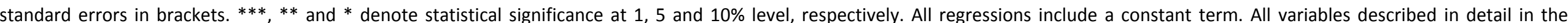
Supplementary Appendix. 
Table 6

Measures of historical prosperity and exposure to UV radiation

\begin{tabular}{|c|c|c|c|c|c|c|c|}
\hline \multirow{3}{*}{ Dependent variable: } & 1 & 2 & 3 & 4 & 5 & 6 & 7 \\
\hline & \multicolumn{3}{|c|}{ Population density in: } & \multicolumn{4}{|c|}{ Real GDP per capita in: } \\
\hline & $1 \mathrm{CE}$ & $1000 \mathrm{CE}$ & $1500 \mathrm{CE}$ & 1820 & 1900 & 1950 & 1950 \\
\hline (log) UV & $\begin{array}{c}-0.71 \\
{[0.69]}\end{array}$ & $\begin{array}{c}-0.84 \\
{[0.61]}\end{array}$ & $\begin{array}{c}-0.92 \\
{[0.65]}\end{array}$ & $\begin{array}{c}0.12 \\
{[0.32]}\end{array}$ & $\begin{array}{l}-0.71 \\
{[0.91]}\end{array}$ & $\begin{array}{c}-1.87 * * * \\
{[0.61]}\end{array}$ & $\begin{array}{c}-3.27^{* *} \\
{[1.46]}\end{array}$ \\
\hline Observations & 127 & 127 & 127 & 42 & 41 & 111 & 41 \\
\hline R-squared & 0.79 & 0.76 & 0.78 & 0.93 & 0.88 & 0.74 & 0.91 \\
\hline Partial R-squared & 0.01 & 0.01 & 0.02 & 0.01 & 0.03 & 0.10 & 0.36 \\
\hline Additional controls & \multicolumn{3}{|c|}{ All controls (with latitude and elevation FEs) } & \multicolumn{4}{|c|}{ All controls (with latitude and elevation FEs) } \\
\hline Number of add controls & 27 & 27 & 27 & 26 & 26 & 27 & 26 \\
\hline
\end{tabular}

Joint significance of the additional control variables (p-values for the H0: all regressors [except UV] are jointly insignificant):
All controls
(with latitude and elevation FEs)
0.00
0.00
0.00
0.00
0.00
0.00

Notes: OLS regressions. The dependent variable in columns 1-3 is population density in the years 1, 1000, and 1500 CE. The dependent variable in columns 4-7 is (log) real GDP per capita in the years 1820, 1900, and 1950. Historical population density and levels of GDP per capita data are from Maddison (2000). UV is a population weighted index of the exposure to ulraviolet radiation (see Supplementary Appendix for details). The R-squared from an OLS regression, where all listed additional controls are partialled out, is reported as the Partial R-squared in each column. Robust standard errors in brackets. All controls are: latitude FEs, elevation FEs, (average 1990-2008) temperature, (average 1990-2008) precipitation, (log) country area (sq km), distance to ocean (km), distance to major rivers ( $\mathrm{km}$ ), (log) area (sq km), timing passed since the Neolithic revolution ('000 years), (log) agricultural suitability index, the percentage of land in tropical and subtropical zones, and (area weighted, average) number of frost days per year. Robust standard errors in brackets. ${ }^{* * *}, * *$ and $*$ denote statistical significance at 1,5 and $10 \%$ level, respectively. All regressions include a constant term. All variables described in detail in the Supplementary Appendix. 
Table 7

Real GDP per worker, fertility decline, cataract prevalence, and exposure to UV

\begin{tabular}{|c|c|c|c|c|c|c|}
\hline \multirow{3}{*}{ Dependent variable: } & 1 & 2 & 3 & 4 & 5 & 6 \\
\hline & $\begin{array}{l}\text { Year of the ferility } \\
\text { decline }\end{array}$ & \multicolumn{5}{|c|}{ (log) Real GDP per worker, 2004} \\
\hline & OLS & oLs & oLs & OLS & OLS & 2SLS - IV \\
\hline$(\log )$ UV & $\begin{array}{c}33.3^{* * *} \\
{[10.4]}\end{array}$ & $\begin{array}{c}-1.29 * * \\
{[0.51]}\end{array}$ & & & $\begin{array}{c}-0.50 \\
{[0.49]}\end{array}$ & \\
\hline Year of the ferility decline & & & $\begin{array}{l}-0.019 * * * \\
{[0.0053]}\end{array}$ & & $\begin{array}{c}-0.017^{* * *} \\
{[0.0054]}\end{array}$ & $\begin{array}{l}-0.015 * * * \\
{[0.0053]}\end{array}$ \\
\hline (log) Cataract prevalence, 2004 & & & & $\begin{array}{c}-0.24 * * * \\
{[0.081]}\end{array}$ & $\begin{array}{l}-0.16^{*} \\
{[0.088]}\end{array}$ & $\begin{array}{l}-0.53 \\
{[0.36]}\end{array}$ \\
\hline Observations & 120 & 120 & 120 & 120 & 120 & 120 \\
\hline R-squared & 0.80 & 0.67 & 0.70 & 0.67 & 0.71 & 0.68 \\
\hline Partial R-squared & 0.08 & 0.05 & 0.15 & 0.05 & 0.18 & 0.08 \\
\hline Additional controls & \multicolumn{6}{|c|}{ All controls (with latitude and elevation levels) } \\
\hline Number of additional controls & 14 & 14 & 14 & 14 & 14 & 14 \\
\hline
\end{tabular}

Endogenous variable

Instrument

Kleibergen Paap F statistic

Anderson Rubin weak id Chi-sq test (p-value)

(log) Cataract prevalence, 2004

$(\log )$ UV

8.52

0.11

Joint significance of the additional control variables (p-values for the HO: all regressors [except UV] are jointly insignificant)

All controls

(with latitude and elevation levels)
0.00

0.00

0.00

0.00

0.00

0.00

Notes: OLS regressions in columns 1-6, and a 2SLS-IV regression in column 7. The dependent variable in column 1 is the timing of the fertility decline (Reher, 2004). The dependent variable in columns 2-6 is (log) real GDP per worker in 2004. UV is a population weighted index of the exposure to ulraviolet radiation (see Supplementary Appendix for details). Cataract prevalence is measured as the number of years lost due to disability, for incident cases of this disease (expressed as a rate per 100,000 people between 15 and 59), estimated by WHO (2004). The R-squared from an OLS regression, where all listed additional controls are partialled out, is reported as the Partial R-squared in each column. Robust standard errors in brackets. All controls are: (log) absolute latitude (degrees), (log) elevation ('O00 m), (average 1990-2008) temperature, (average 1990-2008) precipitation, (log) country area (sq km), distance to ocean (km), distance to major rivers ( $\mathrm{km}$ ), (log) area (sq $\mathrm{km})$, timing passed since the Neolithic revolution ('000 years), (log) agricultural suitability index, the percentage of land in tropical and subtropical zones, and (area weighted, average) number of frost days per year. Robust standard errors in brackets. ***,** and * denote statistical significance at 1,5 and $10 \%$ level, respectively.

All regressions include a constant term. All variables described in detail in the Supplementary Appendix. 
Table 8

Lights by night and exposure to UV: Pixel level analysis in China and USA

\begin{tabular}{|c|c|c|c|c|c|c|c|c|c|c|c|c|}
\hline & 1 & 2 & 3 & 4 & 5 & 6 & 7 & 8 & 9 & 10 & 11 & 12 \\
\hline Dependent variable: & \multicolumn{12}{|c|}{ (log) Intensity of lights by night, 2004} \\
\hline Granularity: & \multicolumn{4}{|c|}{$1 \times 1$} & \multicolumn{4}{|c|}{$2 \times 2$} & \multicolumn{4}{|c|}{$4 \times 4$} \\
\hline Country: & USA & China & USA & China & USA & China & USA & China & USA & China & USA & China \\
\hline (log) UV & $\begin{array}{c}-0.90^{* * *} \\
{[0.23]} \\
(0.27)\end{array}$ & $\begin{array}{c}0.14 \\
{[0.09]} \\
(0.12)\end{array}$ & $\begin{array}{c}-0.89 * * * \\
{[0.03]} \\
(0.29)\end{array}$ & $\begin{array}{l}0.11 * \\
{[0.07]} \\
(0.11)\end{array}$ & $\begin{array}{c}-1.09 * * * \\
{[0.26]} \\
(0.37)\end{array}$ & $\begin{array}{l}0.042 \\
{[0.13]} \\
(0.11)\end{array}$ & $\begin{array}{c}-1.09 * * * \\
{[0.02]} \\
(0.39)\end{array}$ & $\begin{array}{l}-0.045 \\
{[0.08]} \\
(0.13)\end{array}$ & $\begin{array}{c}-1.15^{* * *} \\
{[0.36]} \\
(0.33)\end{array}$ & $\begin{array}{c}0.074 \\
{[0.17]} \\
(0.1)\end{array}$ & $\begin{array}{c}-1.16^{* * *} \\
{[0.00045]} \\
(0.35)\end{array}$ & $\begin{array}{l}0.072 \\
{[0.10]} \\
(0.15)\end{array}$ \\
\hline Observations & 1,243 & 1,079 & 1,243 & 1,079 & 362 & 303 & 362 & 303 & 116 & 89 & 116 & 89 \\
\hline R-squared & 0.22 & 0.22 & 0.22 & 0.31 & 0.45 & 0.33 & 0.46 & 0.45 & 0.65 & 0.58 & 0.66 & 0.64 \\
\hline Partial R-squared & 0.01 & 0.00 & 0.01 & 0.00 & 0.05 & 0.00 & 0.05 & 0.00 & 0.10 & 0.00 & 0.10 & 0.00 \\
\hline Additional controls & & & & & All controls & with latit & de and elev & ation levels & & & & \\
\hline Number of additional controls & 8 & 8 & 8 & 8 & 8 & 8 & 8 & 8 & 8 & 8 & 8 & 8 \\
\hline Fixed effects & - & - & Language & Language & - & - & Language & Language & - & - & Language & Language \\
\hline Number of fixed effects & - & - & 21 & 46 & - & - & 20 & 36 & - & - & 5 & 23 \\
\hline Std errors: robust/clustered by: & Robust & Robust & Language & Language & Robust & Robust & Language & Language & Robust & Robust & Language & Language \\
\hline
\end{tabular}

Joint significance of the additional control variables (p-values for the HO: all regressors [except UV] are jointly insignificant):
All controls
$0.00 \quad 0.00$
0.00
0.00
0.00
0.00
0.00
0.00
0.00
0.00
0.00
0.00

Notes: OLS regressions. The dependent variable is an index of the intensity of ligths at night in 2004, produced by NASA. Each observation is for a geographic pixel of $1 \times 1,2 \times 2$, or $4 \times 4$ degrees of latitude and longitude, respectively. UV is a population weighted index of the exposure to ulraviolet radiation (see Supplementary Appendix for details). The R-squared from an OLS regression, where all listed additional controls are partialled out, is reported as the Partial R-squared in each column. All controls are: (log) absolute latitude (degrees), (log) elevation ('000 m), (average 1990-2008) temperature, (average 1990-2008) precipitation, (log) country area (sq km), distance to ocean (km), distance to major rivers (km), and distance to the capital of the country $(\mathrm{km})$. Language FEs computed from the World Language Mapping System. Standard errors clustered by country or predominant language area reported in brackets. Conley standard errors, robust to spatial autocorrelation, are reported in parentheses. ${ }^{* *},{ }^{* *}$ and $*$ denote statistical significance at 1,5 and $10 \%$ level, respectively, based on the clustered standard errors. All regressions include a constant term. All variables described in detail in the Supplementary Appendix. 